\title{
Treatment of latent infection with \\ Mycobacterium tuberculosis: update 2010
}

\author{
C.C. Leung*, H.L. Rieder ${ }^{\#, \text {, }}$ C. Lange ${ }^{+}$and W.W. Yew ${ }^{\S}$
}

ABSTRACT: Much remains unknown about latent infection with Mycobacterium tuberculosis. Existing immunodiagnostic tools for this condition have various limitations, most importantly in their ability to predict disease. Randomised controlled trials have established protective efficacy of isoniazid therapy for 6-12 months among non-HIV-infected and HIV-infected subjects. While efficacy may reach $90 \%$, acceptance and adherence to prolonged therapy are less than desired. Rifampicin plus pyrazinamide for 2 months, though efficacious, has been associated with excess hepatotoxicity in non-HIV-infected persons. Isoniazid plus rifampicin for $\mathbf{3}$ months has proven efficacy, but adverse effects may be more frequent than isoniazid or rifampicin monotherapy. Rifampicin monotherapy for 3-4 months is well tolerated, but efficacy data are currently limited, and concerns remain over possible selection of rifampicin-resistant mutants. For contacts of patients with multidrug-resistant tuberculosis, expert opinions differ on whether to treat with at least two drugs or just a fluoroquinolone, and for how long. With the existing diagnostic and treatment tools, efficacy of preventive therapy does not necessarily translate into field effectiveness. A targeted approach is required to maximise cost-effectiveness. Each geographic region needs to set its own priority after taking into account available scientific data and local circumstances.

\section{KEYWORDS: Latent infection, preventive therapy, tuberculosis}

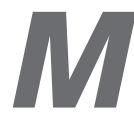
ycobacterium tuberculosis has been a coevolving pathogen during the major phases of human evolution [1]. The historically best documented epidemic of tuberculosis, the disease caused by $M$. tuberculosis, has emerged in parallel with industrialisation and urbanisation some $250 \mathrm{yrs}$ ago in the Western world [2]. While it has declined for a long time in that area of the world to now very low levels, it has emerged in other parts of the world as a result of population growth, migration and the devastating impact of infection with the HIV over the past 30 yrs. Despite important recent advances in its diagnosis [3] and treatment [4], tuberculosis remains one of the leading causes of death worldwide [5]. In 2008, there were an estimated 9.4 million incident cases of tuberculosis, 11.1 million prevalent cases, 1.3 million deaths among
non-HIV-infected persons and an additional 0.52 million deaths among HIV-infected persons [5]. Despite the worldwide implementation of the World Health Organization (WHO)'s recomincidence rate has peaked at 143 (95\% credible range 136-151) cases per 100,000 population since 2004 [5].

The WHO reports that one-third of the world population is infected by the tubercle bacillus [6]. As this estimation cannot be verified with currently available methods, it is, at best, an uncertain estimate of the number of persons in the world who have at one time or the other become latently infected with $M$. tuberculosis [7]. The majority of individuals with $M$. tuberculosis infection is likely to be asymptomatic, and the mended DOTS Strategy, the estimated global

Previous articles in this series: No. 1: Erkens CGM, Kamphorst M, Abubakar I, et al. Tuberculosis contact investigation in low prevalence countries: a European consensus. Eur Respir J 2010; 36: 925-949. No. 2: Solovic I, Sester M, Gomez-Reino JJ, et al. The risk of tuberculosis related to tumour necrosis factor antagonist therapies: a TBNET consensus statement. Eur Respir J 2010; 36: 1185-1206. No. 3: Schutz C, Meintjes G, Almajid F, et al. Clinical management of tuberculosis and HIV-1 co-infection. Eur Respir J 2010; 36: 1460-1481. No. 4: Yew WW, Lange C, Leung CC. Treatment of tuberculosis: update 2010. Eur Respir J 2011; 37: 441-462.

\section{AFFILIATIONS}

*Tuberculosis and Chest Service, Dept of Health, and

${ }^{\S}$ Tuberculosis and Chest Unit, Grantham Hospital, Hong Kong, China.

\# International Union against Tuberculosis and Lung Disease, Paris, France.

"Institute of Preventive and Social Medicine, University of Zurich, Zurich, Switzerland.

${ }^{+}$Division of Clinical Infectious Diseases, Medical Clinic, Research Center Borstel, Borstel, Germany.

CORRESPONDENCE

C.C. Leung

Wanchai Chest Clinic

99 Kennedy Road

Wanchai

Hong Kong

China

E-mail: cc_leung@dh.gov.hk

Received:

May 212010

Accepted after revision:

July 162010

First published online:

August 62010 
infecting organism could have been eliminated subsequently in a substantial proportion of them [8]. Latent infection with M. tuberculosis is pragmatically defined as presumptive infection with $M$. tuberculosis complex, as evidenced by a positive tuberculin skin test reaction and/or a positive interferon- $\gamma$ release assay (IGRA) result without any sign of clinically or radiologically manifest disease. Direct identification of individuals who are latently infected with live $M$. tuberculosis without active disease is not possible. The term "latent infection with M. tuberculosis" (often also somewhat confusingly termed "latent tuberculosis infection" abbreviated as "LTBI") is thus misleading, as immunodiagnostic tests ascertain a state of persistent $M$. tuberculosis-specific immune responses rather than true latent infection with $M$. tuberculosis [7]. In this article, we pragmatically refer to individuals with latent infection with $M$. tuberculosis as those with an adaptive immune response in the form of a positive tuberculin skin test and/or M. tuberculosis-specific IGRA who are potentially infected with M. tuberculosis.

Large numbers of tuberculosis cases will continue to arise from a pool of individuals with latent infection with $M$. tuberculosis by endogenous reactivation. Indeed, with the progressive reduction in ongoing transmission and continuing ageing of the worlds' population, tuberculosis arising from endogenous reactivation of latent infection with $M$. tuberculosis now constitutes the majority of reported tuberculosis cases in low and intermediate tuberculosis burden areas [9].

Treatment of latent infection with $M$. tuberculosis has been started quite early subsequent to the re-discovery of isoniazid in 1951 [10]. Although the drug has been shown in randomised controlled trials to be efficacious in reducing the risk of tuberculosis among latently infected subjects with or without HIV coinfection [11, 12], long courses of treatment lasting 6-12 months are currently recommended. The adherence to isoniazid preventive therapy and the field effectiveness are often suboptimal. There are also concerns over adverse effects of isoniazid preventive therapy, especially hepatotoxicity $[11,12]$. Attempts have therefore been made to identify shorter and, perhaps, better tolerated drugs and regimens. Attention is naturally focused on two of the existing drugs, rifampicin and pyrazinamide, that have shown very good sterilising activity in both animal studies $[13,14]$ and human trials $[15,16]$. Newer drugs showing good sterilising activities in animal studies [17-22] might also be effective for the prevention of tuberculosis in humans.

This article will examine the existing approaches for the treatment of latent infection with $M$. tuberculosis. Where appropriate, evidence levels for the recommended treatment regimens are given in accordance with the grading system of the Scottish Intercollegiate Guidelines Network (provided as an appendix to this article) [23].

\section{THE LATENT INFECTION STATE}

M. tuberculosis is able to persist within the human host for long periods without causing clinically manifest disease. Chronic persistence within the human host involves alterations of the bacillary metabolic processes with apparent arrest or slowing of multiplicative activities [24-27]. Whether "dormancy" is the correct term for this state of altered metabolism has been a matter of debate. The factors and mechanisms for such altered state of metabolism are only beginning to be elucidated, and adaptive bacillary response to hypoxia within the granuloma could be one of the factors [28]. The ability of M. tuberculosis to enter a persistent phase carries major implications on its preventive treatment, as the current drugs are not expected to act when their target metabolic processes are switched off.

Using forms of environmental stress, such as hypoxia or acid suppression, in vitro models have been developed, both to elucidate the underlying mechanisms of latent infection with $M$. tuberculosis and to study the action of drugs under such conditions [28-31]. In one such model, the Wayne model, a sealed, standing culture became progressively more hypoxic on incubation, with a concomitant shift in $M$. tuberculosis physiology [29]. Molecular signatures of such hypoxic stress responses are accumulating, but correlations with human infection/disease status are still unclear [28, 32-34].

Models of latent infection with $M$. tuberculosis have been developed in mice, guinea pigs, zebrafishes, rabbits and nonhuman primates [28]. In the Cornell model, mice infected with M. tuberculosis are treated with isoniazid and pyrazinamide to induce a temporary "latent" state, during which no detectable bacilli can be recovered by organ culture and guinea pig inoculation [35]. This and similar kinds of models have been used extensively to study the action of drugs on latent infection with $M$. tuberculosis [13, 14, 17, 19, 28].

\section{DIAGNOSTIC ISSUES}

In contrast to the various clinical manifestations [36] and high fatality of untreated tuberculosis [37], latent infection with M. tuberculosis is, by definition, asymptomatic, and latently infected individuals do not shed bacilli into the environment and are thus noninfectious. Intervention on such latent infection state is justified primarily because of the risk of developing disease. Among young individuals with positive tuberculin skin tests identified during tuberculosis contact tracing, $\sim 5 \%$ will develop active disease in the first 5 yrs and another $5 \%$ in the rest of their lifetime [38-41]. The risk is, however, modulated by age at infection [42] and many other host factors (table 1) [39, 43-46]. In a more recent study from Germany, six (15\%) out of 41 untreated close contacts with a positive result by IGRA developed active tuberculosis within 2 yrs following contact with an infectious index case [47]. Most of the tuberculosis cases in that study involved ethnic minorities, and only two of them were culture confirmed. A somewhat lower proportion was observed in another study from Turkey, in which four $(7 \%)$ out of 54 untreated children with a positive IGRA result during contact examination developed active tuberculosis after 93 person-yrs of follow-up [48]. IGRA did not appear to perform better than the tuberculin skin test among tuberculosis contacts in the Gambia, in which most of the tuberculosis cases were detected during the initial examination, and subsequent disease rate among subjects with a positive result for either test was much lower [49].

Table 2 summarises the characteristics of the existing diagnostic tools for latent infection with $M$. tuberculosis [39, 47-51]. With the low bacillary load and suppressed metabolic manifestations, the diagnosis of latent infection with $M$. tuberculosis has, all along, depended on the detection of host response, 


\begin{tabular}{|c|c|c|}
\hline $\begin{array}{l}\text { Incidence } \\
\text { (TB) for se }\end{array}$ & $\begin{array}{l}\text { relative risk } \\
\text { d risk facto }\end{array}$ & ctive tuberculosis \\
\hline & Incidence $^{\#}$ & Relative disease risk \\
\hline \multicolumn{3}{|l|}{ Recent TB infection } \\
\hline Infection <1 yr past & 12.9 & \\
\hline Infection 1-7 yrs past & 1.6 & \\
\hline Old TB scar & $2.0-13.6$ & \\
\hline HIV infection & $35.0-162$ & \\
\hline \multicolumn{3}{|l|}{ Injection drug use } \\
\hline HIV seropositive & 76.0 & \\
\hline Other & 10.0 & \\
\hline \multicolumn{3}{|l|}{ Smoking } \\
\hline Current smokers & & 2.63 \\
\hline Ex-smokers & & 1.41 \\
\hline Never smokers & & 1.00 \\
\hline Passive smoking & & 1.49 \\
\hline \multicolumn{3}{|l|}{ Body mass index } \\
\hline$\geqslant 30$ & & 0.38 \\
\hline 25 to $<30$ & & 0.58 \\
\hline 23 to $<25$ & & 0.74 \\
\hline 18.5 to $<23$ & & 1.00 \\
\hline$<18.5$ & & 2.11 \\
\hline Silicosis & 68 & 30 \\
\hline \multicolumn{3}{|l|}{ DM } \\
\hline DM versus no DM & & $1.8-4.1$ \\
\hline HBA $1 \mathrm{c} \geqslant 7 \%$ versus $<7 \%$ & & 3.1 \\
\hline Chronic renal failure & & $10.0-25.3$ \\
\hline Gastrectomy & & $2-5$ \\
\hline Jejunoileal bypass & & $27-63$ \\
\hline Renal transplant & & 37 \\
\hline Heart transplant & & $20-74$ \\
\hline Head and neck carcinoma & & 16 \\
\hline
\end{tabular}

DM: diabetes mellitus. * : among tuberculin-positive subjects per 1,000 person-yrs.

rather than the presence/activity of the pathogen itself [50]. Immunodiagnostic methods may underperform among those who fail to mount an adequate immune response [39, 50, 52, 53]. More importantly, currently available immunodiagnostic tests are unable to differentiate individuals who will subsequently develop tuberculosis from those who will not [39, 47-49]. They also fail to distinguish recent infection from remote infection that carries a much lower risk for the development of active disease [38, 39, 50,51]. This may pose another major obstacle in areas and/or age groups with a high background prevalence of latent infection with $M$. tuberculosis [6]. Ongoing research is focusing on antigens expressed during different metabolic phases of M. tuberculosis [54] and/or cytokines expressed by the human host [55]. It is hoped that this may help to improve the performance of immunodiagnostic tests in future.

\section{MECHANISMS OF DRUG ACTION}

From observations in both animal and human studies, it has been postulated that a patient with tuberculosis can harbour four hypothetical populations of organisms (fig. 1) [24]. Three major actions are proposed for the currently available antituberculosis drugs [56]: 1) bactericidal action (ability to kill actively growing bacilli rapidly), often assessed by the decrease in quantitative sputum culture bacillary count in the initial few days of treatment [57]; 2) sterilising action (ability to kill persisters under acid inhibition or with spurts of metabolism), as reflected by the ability to prevent relapse or its proxy marker, such as 2-month sputum culture conversion rate [58]; and 3) prevention of emergence of bacillary resistance to drugs.

Of the currently available antituberculosis drugs, isoniazid has the highest early bactericidal effect against rapidly growing tubercle bacilli, while rifampicin and pyrazinamide are thought to have the greatest sterilising effects against those with spurts of metabolism and under acid inhibition respectively $[56,57]$.

\section{CLINICAL TRIALS WITH ISONIAZID}

After the rediscovery of isoniazid there followed exploration of treatment with isoniazid alone and in combination with paraaminosalicylic acid or streptomycin in the treatment of tuberculosis with encouraging results [59]. Encouraging data also emerged in its use to prevent experimental tuberculosis in guinea pigs [60]. However, there were concerns over its efficacy in preventing disease or infection as well as the possible emergence of drug resistance [10]. A series of largescale clinical trials were initiated by the United States Public Health Service (USPHS) within programme settings to address this important issue. The first of these studies began in 1955 but it only examined whether the frequency of complications of primary tuberculosis could be decreased by the use of isoniazid [61]. Four subsequent randomised controlled trials were started in the 1950s and were completed in the 1960s, including a total of 7,333 villagers in Alaska [62], 27,857 household contacts $[63,64]$, and 24,838 patients in psychiatric institutions [65]. Cluster randomisation was done by household, village, or hospital ward. Isoniazid or matching placebo was given for $1 \mathrm{yr}$, at a dose of $300 \mathrm{mg}$ daily or $5 \mathrm{mg} \cdot \mathrm{kg}^{-1}$ for children. These studies, by their sheer sizes, helped to establish the efficacy of isoniazid in the treatment of latent infection with M. tuberculosis.

Follow-up data from the Alaskan study $[62,66]$ also suggested that the protective effect of isoniazid preventive chemotherapy persists for up to $19 \mathrm{yrs}$, even though the offering of open-label treatment to all participants might have affected the accurate assessment of protective effect after 10 yrs. Prolonged followup of a cohort of children up to $30 \mathrm{yrs}$ also supports a longlasting protective effect [67]. It therefore appears that, among non-HIV infected subjects in areas without excessive risk of ongoing transmission, treatment of latent infection with M. tuberculosis produces a lasting effect.

Table 3 summarises the results of randomised controlled trials on the treatment of latent infection with $M$. tuberculosis with a placebo/no treatment arm in non-HIV infected persons [62-65, 68-74]. In a meta-analysis involving 73,375 subjects in 11 placebo-controlled randomised trials, treatment with isoniazid for $6-12$ months reduced the risk of tuberculosis by $60 \%$ (risk ratio (RR) $0.40,95 \%$ CI $0.31-0.52$ ) over 2 yrs or longer (grade A) [11]. Preventive therapy reduced deaths from tuberculosis, but not all-cause mortality. 
TABLE 2 Comparison between available tests for latent tuberculosis infection

TST

QuantiFERON ${ }_{\mathbb{R}}$ TB-Gold/IT

ESAT6, CFP10, TB7.7 (specific; absent in BCG and most NTM)

Whole blood interferon assay; single visit

High; fresh blood delivery; no cell separation High

No

No; result not affected by serial testing (may be affected by prior TST) Single

Not fully clarified yet Not fully clarified yet Not fully clarified yet

Does not distinguish

Does not distinguish adequately Higher

\section{Less affected}

Less affected

QFT-Gold: 73-82\%; QFT-Gold IT: 63-78\%

No BCG: $98-100 \%$; BCG: $94-98 \%$
T-Spot.TB

ESAT6, CFP10 (specific, absent in BCG and most NTM)

Blood monocyte spot test; single visit

Highest; fresh blood delivery; cell separation required Highest

No

No; result not affected by serial testing (may be affected by prior TST) Single

Not fully clarified yet Not fully clarified yet Not fully clarified yet

Does not distinguish

Does not distinguish adequately Higher/highest

Least affected

Less affected

86-93\%

86-100\%
No BCG: 95-99\%; BCG: low and heterogeneous Abundant

Scanty

Scanty

TST: tuberculin skin test; ESAT6: 6 kDa early secretory antigen target; CFP10: 10 kDa culture filtrate antigen; BCG: bacille Calmette-Guérin; NTM: nontuberculous mycobacteria. ${ }^{\#}$ : positive rate among patients with culture-confirmed tuberculosis; ${ }^{\bullet}$ : negative rate among low-risk individuals.

No significant difference was found in the risk reduction between 6 months (RR 0.44,95\% CI 0.27-0.73) and 12 months (RR $0.38,95 \%$ CI $0.28-0.50$ ) of isoniazid [11]. In the International Union Against Tuberculosis (IUAT) trial, the only study that included direct comparison between 6 and 12 months of isoniazid, a total of 28,000 persons with fibrotic pulmonary lesions compatible with tuberculosis were followed for 5 yrs after receiving varying durations of isoniazid at $300 \mathrm{mg}$ daily

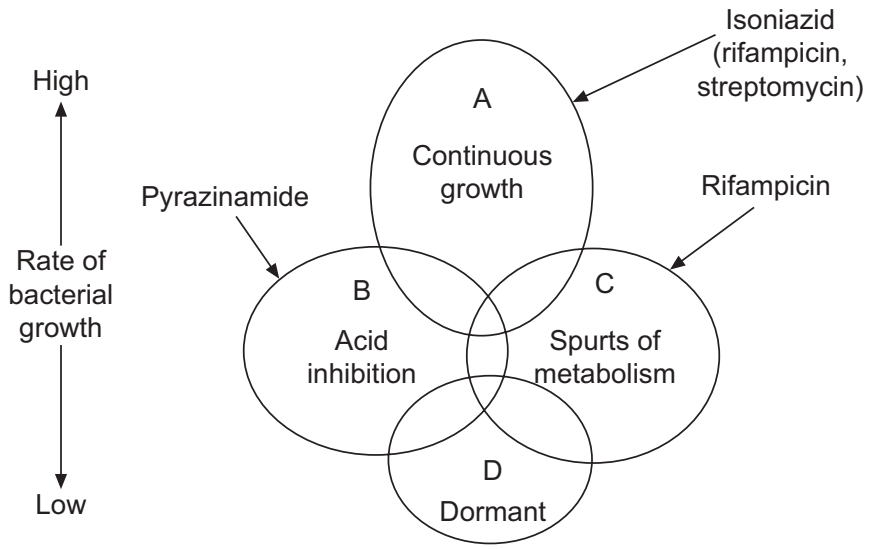

FIGURE 1. Hypothetical components of the bacterial population in active tuberculosis. given in 35-day packages for self-administered treatment [72]. On an intention to treat basis, 12 weeks, 24 weeks and 52 weeks of isoniazid reduced the risk of tuberculosis within 5 yrs by $21 \%, 65 \%$ and $75 \%$ respectively, as compared with placebo. There was no statistical difference between the effectiveness of the 24-week and 52-week regimens under the study conditions, but both of them prevented significantly more tuberculosis cases than either the 12-week regimen or placebo. Hepatitis occurred at a frequency of $0.12 \%, 0.25 \%, 0.36 \%$, and $0.52 \%$ in the placebo, 12-week, 24-week and 52-week arms respectively. The 24 -week regimen prevented more tuberculosis cases (2.6 versus 2.1 tuberculosis cases) per case of hepatitis than the 52-week regimen.

When analysis was restricted to those participants who took at least $80 \%$ of doses from each calendar package and took all calendar packages for the entire assigned duration ("completercompliers") in the IUAT trial, 12, 24 and 52 weeks of isoniazid reduced the risk of tuberculosis by $31 \%, 69 \%$ and $93 \%$ respectively (all inter-regimen $\mathrm{p}<0.05$ ). Despite possible selection bias in secondary subgroup analyses, such results and the study among Netherlands army recruits [70] suggested considerably higher efficacies might be achievable among adherent patients than the overall effectiveness as observed among all patients. In one of the USPHS household contact studies [63], the subsequent risk of tuberculosis was reduced by $68 \%$ and $16 \%$, respectively, among those taking $\geqslant 80 \%$ of the recommended 


\begin{tabular}{|c|c|c|c|c|c|c|}
\hline TABLE 3 & $\begin{array}{l}\text { ed latent tuberculos } \\
\text { ersons }\end{array}$ & B) infection treatment & Is with a plac & /no treatm & t arm am & non-HIV \\
\hline \multirow[t]{2}{*}{ Lead author [ref.] } & \multirow[t]{2}{*}{ Site (year) } & \multirow[t]{2}{*}{ Target population } & \multirow[t]{2}{*}{ Regimen } & \multicolumn{2}{|c|}{$\begin{array}{l}\text { TB cases } / \text { number } \\
\text { treated }^{\#}\end{array}$} & \multirow[t]{2}{*}{ RR (95\% Cl) } \\
\hline & & & & Treatment & Control & \\
\hline Ferebee [63] & USA (1962) & Household contacts & H 12 month & $8 / 8478$ & $36 / 8311$ & $0.22(0.10-0.47)$ \\
\hline Ferebee [65] & USA (1963) & Mental institution residents & H 12 month & $61 / 12339$ & $173 / 12499$ & $0.36(0.27-0.48)$ \\
\hline Egsmose $[68]$ & Kenya (1965) & Household contacts & H 12-24 month & $7 / 325$ & 18/301 & $0.36(0.15-0.85)$ \\
\hline Del Castillo [69] & The Philippines (1965) & Household contacts & H 12 month & $16 / 126$ & $22 / 167$ & $0.96(0.53-1.76)$ \\
\hline VeENING $[70]$ & The Netherlands (1968) & Recent TST converters & H 12 month & $1 / 133$ & $12 / 128$ & $0.08(0.01-0.61)$ \\
\hline THомPSon [72] & & & H 12 month & $24 / 6919$ & & $0.25(0.16-0.39)$ \\
\hline \multirow[t]{3}{*}{ GIRLING [73] } & Hong Kong (1992) & Silicosis patients & H 6 month & $20 / 100$ & $34 / 99$ & $0.58(0.36-0.94)$ \\
\hline & & & HR 3 month & $19 / 87$ & & $0.64(0.39-1.03)$ \\
\hline & & & R 3 month & $17 / 103$ & & $0.48(0.29-0.80)$ \\
\hline JoHN [74] & India (1994) & $\begin{array}{c}\text { Renal transplant/dialysis } \\
\text { patients }\end{array}$ & H 12 month & $7 / 92$ & $10 / 92$ & $0.70(0.28-1.76)$ \\
\hline
\end{tabular}

RR: risk ratio; H: isoniazid; TST: tuberculin skin test; R: rifampicin. " : data for longest period of follow-up within 2-5 yrs used for analysis.

number of pills for $\geqslant 10$ months and $<10$ months. In the Alaskan study, the decline in the case rate became nearly horizontal at 9-10 months when the tuberculosis case rate was plotted against months of treatment taken [75, 76]. Based on these observations, COMSTOCK and co-workers [75, 76] inferred that 9-10 months of isoniazid was the optimal duration, which formed the basis for the revised current recommendation in the USA [39]. Extending treatment beyond 12 months did not appear to reduce the tuberculosis risk in the Alaskan study and the Veterans Administration Cooperation Study [71].

The use of a daily isoniazid dosing schedule is well supported by randomised controlled trials (grade A) [11]. Twice-weekly isoniazid dosing at $15 \mathrm{mg} \cdot \mathrm{kg}^{-1}$ (maximum $900 \mathrm{mg}$ ) is also used in the USA to facilitate direct observation in the treatment of latent infection with M. tuberculosis (grade D) [39, 77]. Such dosing schedule has not been tested in randomised controlled trials among non-HIV infected persons (table 3). Its likely efficacy is extrapolated mainly from a clinical trial on active tuberculosis [78].

In children, randomised trials are available only for the 12month regimen. Extrapolation from adult studies may be reasonable. However, a recent study found a low peak serum concentration of isoniazid among young South African children (median age $3.2 \mathrm{yrs}$ ) given isoniazid daily at 4-6 $\mathrm{mg} \cdot \mathrm{kg}^{-1}$, especially among intermediate or fast acetylators [79], and higher daily doses of $8-12 \mathrm{mg} \cdot \mathrm{kg}^{-1}$ may be required to achieve similar isoniazid concentrations as in adults. With the high serum level to minimal inhibitory concentration ratio for isoniazid [56] and the use of isoniazid at daily dosage of $5 \mathrm{mg} \cdot \mathrm{kg}^{-1}$ among young children in virtually all clinical trials
[11], it remains an open question whether the higher dosage is necessary.

\section{ISONIAZID-RELATED HEPATOTOXICITY}

Many of the earlier trials on isoniazid were conducted before its potential hepatotoxicity was well recognised [10]. At first, the isolated reports of jaundice in the early USPHS clinical trials were not conclusively linked to isoniazid [66]. However, with the subsequent widespread use of the drug in the treatment of latent infection with $M$. tuberculosis in the USA, serum transaminase elevations and other hepatic abnormalities were soon recognised [80]. After the occurrence of 19 cases of hepatitis resulting in two deaths among 2,321 contacts treated with isoniazid in an outbreak [81], the USPHS undertook a major surveillance study among 13,838 persons in 21 participating health departments [82]. In that study, the overall frequency of isoniazid-related hepatitis was 10.3 per 1,000 participants $(1 \%)$, with most of them occurring within the first 3 months of treatment. The hepatitis risk increased sharply with age, with $0 \%, 0.3 \% 1.2 \%$ and $2.3 \%$ among those aged below 20, 20-34, 35-49 and 50-64 yrs, respectively. Daily alcohol consumption was also an important risk factor. Hospitalisation frequency was up to 5.0 per 1,000 treatment initiations. There were eight fatalities with a mortality of 0.6 per 1,000 persons. It is noteworthy that of the eight deaths in the 20-city study, seven occurred in the Baltimore area, which was later shown to have had an excessive increase in cirrhosis of the liver when compared with the 2 yrs earlier and later [83]

In a meta-analysis involving 38,257 subjects treated with isoniazid in six earlier studies, clinical hepatitis ranged from $0.0-2.9 \%$ [84]. The combined frequency was $0.6 \%$ in absence of 
age adjustment. More recently, the frequency of symptomatic hepatitis has been estimated to be one to three per 1,000 persons, and much lower hospitalisation ( 0.1 to 0.2 per 1,000 persons) and mortality ( 0.0 to 0.3 per 1,000 persons) have been reported $[85,86]$. Such a decline might reflect more careful patient selection and active monitoring for early signs of adverse effects during treatment [39].

\section{OTHER ISONIAZID-RELATED ADVERSE DRUG EVENTS}

The adverse drug events from isoniazid are summarised with those of other antituberculosis drugs in table 4 [87-91]. Mild and transient headache, nausea and dizziness were reported in clinical trials of isoniazid among non-HIV infected subjects [11]. Peripheral neuropathy, related to a dose-dependent inhibitory effect of isoniazid on the function of pyridoxine metabolites, is uncommon $(<0.2 \%)$ in healthy individuals. It is more frequently encountered in the chronically alcoholdependent, malnourished persons, pregnant females and HIV-infected subjects [87-89], but it can be prevented as well as treated by pyridoxine. It is not generally held that pyridoxine should be given routinely [92], but it should be prescribed to patients at risk of such complication, including those with underlying nutritional deficiency or higher requirements, and in persons in whom peripheral neuropathy may develop as a result of the underlying condition, thus leading to confusion over the cause. Central nervous system reactions, such as convulsions, encephalopathy, optic neuritis, memory impairment and psychosis, are rare at normal doses. Antinuclear antibody is more common than the actual lupuslike syndrome.

\section{HIV-INFECTED INDIVIDUALS}

In a study by SELWYN et al. [93] in the USA, the risk of tuberculosis among tuberculin skin test-positive and HIVinfected subjects was at least 7.9 cases per 100 person-yrs. The risk of developing tuberculosis increases with the degree of immunosuppression [94], and remains elevated (though at a reduced level) even after the initiation of antiretroviral therapy [95]. Tuberculin skin testing remains a useful primary screening test for the diagnosis of latent infection with $M$. tuberculosis among HIV-infected persons despite possible limitations in sensitivity [96], with 24-fold difference in risk between testpositive and test-negative subjects in the above quoted study [93]. Data on the disease-predicting values of IGRA among HIV-infected persons are still scanty [97].

Table 5 summarises the results of randomised controlled trials on the treatment of latent infection with $M$. tuberculosis with a placebo/no treatment arm among HIV-infected persons

TABLE 4 Adverse reactions to drugs used for treatment of latent tuberculosis infection

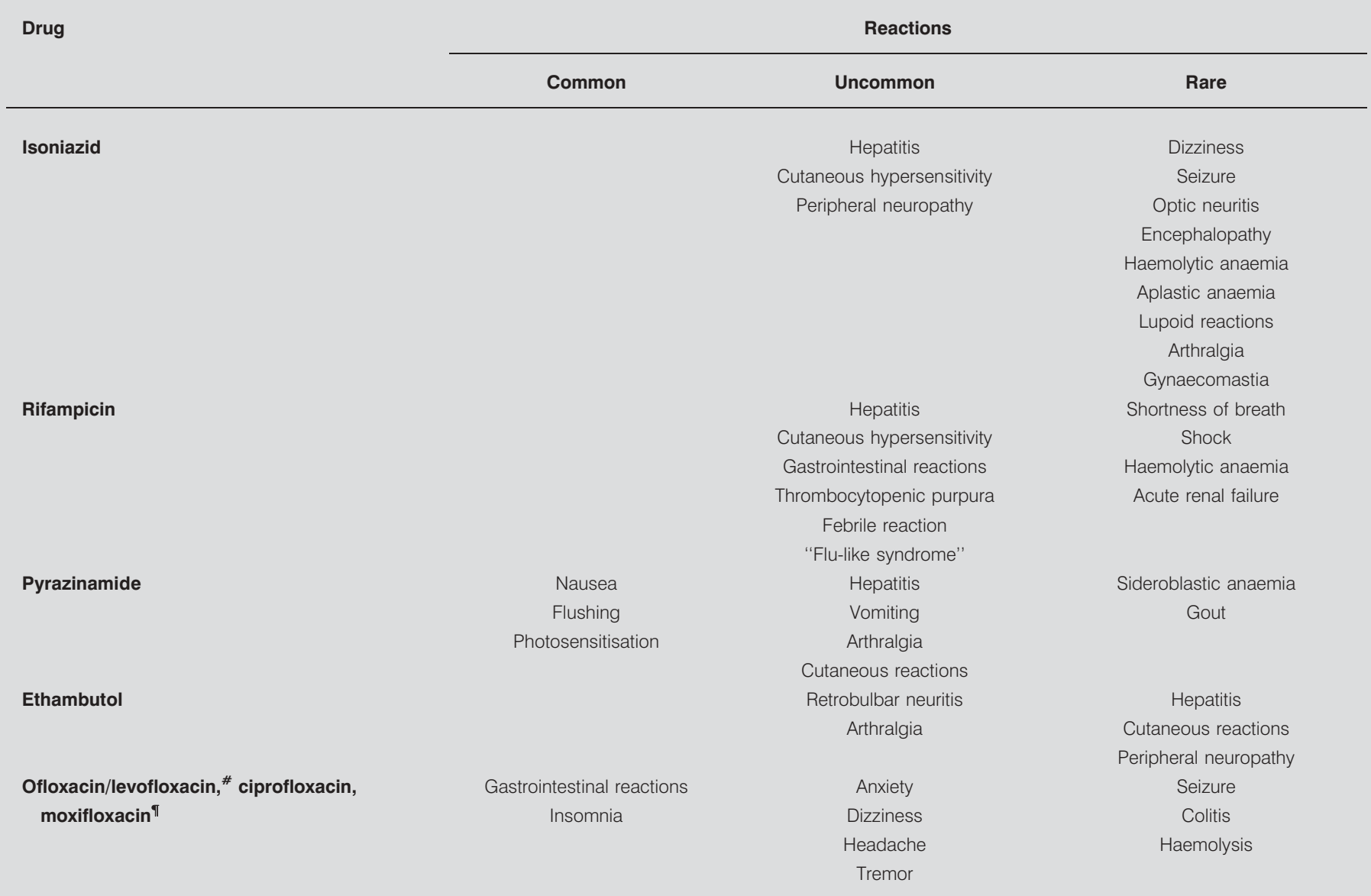

\footnotetext{
\#: levofloxacin is better tolerated than ofloxacin; ${ }^{~}$ : experience on moxifloxacin tolerance is accumulating.
} 


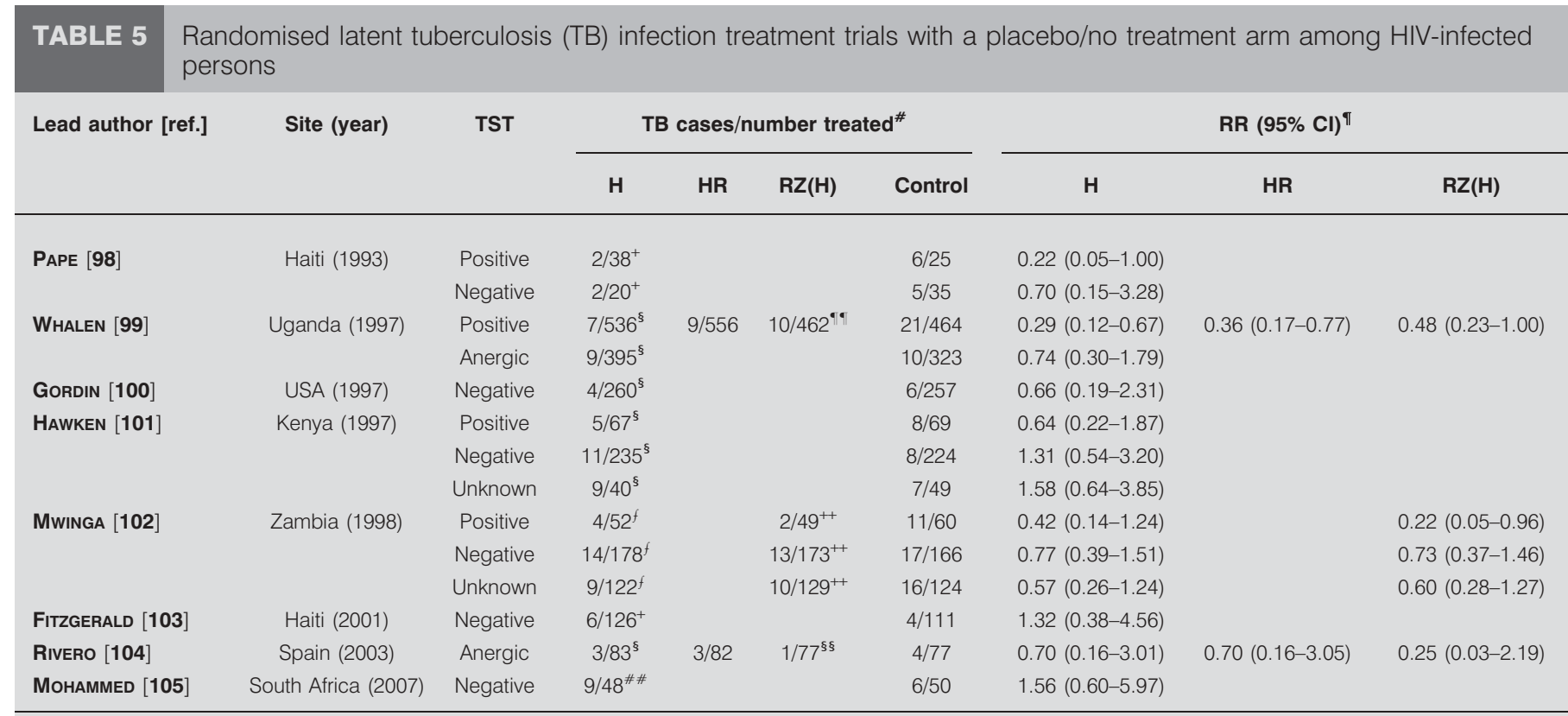

TST: tuberculin skin test; RR: risk ratio; H: isoniazid; HR: isoniazid plus rifampicin daily for 3 months; $R Z(H)$ : rifampicin plus pyrazinamide or rifampicin plus pyrazinamide plus isoniazid for 2-3 months. ${ }^{\#}$ : active TB cases within 1-3 yrs of follow-up (variable and with considerable attrition); "

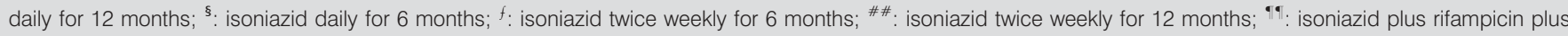

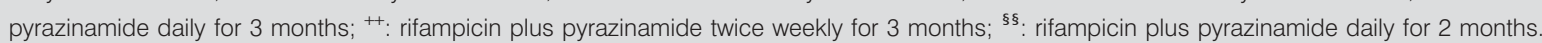

[98-105]. In a randomised controlled trial among HIV-infected subjects in Haiti [98], a 12-month course of isoniazid reduced the incidence rate of tuberculosis from 7.5 to 2.2 per 100 person-yrs (RR 0.29, 95\% CI 0.09-0.91) among HIV-infected subjects. In subgroup analysis, there was significant reduction (RR 0.22, 95\% CI 0.05-1.00) among tuberculin skin test-positive subjects (cut-off $\geqslant 5 \mathrm{~mm}$ ) but not among tuberculin skin testnegative subjects (RR $0.70,95 \%$ CI $0.15-3.28$ ). In this particular study, isoniazid treatment also delayed progression to HIVassociated morbidity including AIDS and death. In a Ugandan trial [99], 6 months of isoniazid significantly reduced tuberculosis risk among tuberculin skin test-positive subjects (RR 0.33 , 95\% CI 0.14-0.77) but not subjects with anergy (RR 0.83, 95\% CI 0.34-2.04). Survival did not differ between the study arms, but anergic subjects had a higher fatality than those with a positive tuberculin skin test. In a follow-up analysis, benefit in tuberculin skin test-positive persons was lost after the first year [106]. No significant protective efficacy was observed for 6 months of isoniazid among HIV-infected subjects after a median follow-up of 1.83 yrs in Kenya, but the small number of tuberculin skin test-positive subjects (67-69 per arm) might not have provided adequate power to pick up any difference [101].

In a randomised controlled trial among HIV-infected subjects with anergy in the USA, tuberculosis was diagnosed in only six of 257 patients in the placebo group and three of 260 patients in the isoniazid group after a mean follow-up of 33 months [100]. As the incidence of tuberculosis was low, it does not support the use of isoniazid treatment in anergic HIV-infected subjects in absence of recent exposure to a case with bacteriologically confirmed tuberculosis of the respiratory tract. There were also no significant differences between the two groups with regard to death, death or the progression of HIV disease, or adverse events.

Only a single randomised controlled trial in Zambia tested 6 months of isoniazid twice a week against placebo among HIV-infected persons [102]. However, only combined analysis of treatment with either 6 months of isoniazid or 3 months of rifampicin plus pyrazinamide against placebo reached statistical significance (RR $0.60,95 \%$ CI $0.40-0.89$ ). The effect of preventive therapy also declined after the first year of the study. By 18 months the rates of tuberculosis in the treated groups were similar to that in the placebo group, even though the cumulative risk of tuberculosis remained significantly lower within the first 2.5 yrs [107].

Among 4,316 HIV-infected subjects in seven trials [98-104, 106, 107] included in a recent meta-analysis [12], treatment with either 6 or 12 months of isoniazid was associated with a significantly lower incidence of tuberculosis (RR 0.67, 95\% CI $0.51-0.87)$. This benefit was more pronounced in individuals with a positive tuberculin skin test (RR $0.36,95 \%$ CI $0.22-0.61$ ) (grade A), but failed to achieve statistical significance among those who had a negative tuberculin skin test (RR 0.86, 95\% CI 0.59-1.26) (insufficient evidence). Overall, adverse events leading to stopping treatment occurred in $2.8 \%$ of those receiving isoniazid, compared to $1.8 \%$ of the placebo arm (RR 1.66, 95\% CI 1.09-2.51). The reduction in mortality just reached statistical significance among individuals with a positive tuberculin skin test (RR 0.74, 95\% CI 0.55-1.00). Despite the delay in HIV progression that was observed with isoniazid treatment in the Haiti trial [98], confirmation of such an effect awaits further trials. It is not possible to determine whether the effects of treatment are influenced by the 


\begin{tabular}{|c|c|c|c|c|c|c|c|c|c|}
\hline \multirow{3}{*}{$\begin{array}{l}\text { TABLE } 6 \text { Ra } \\
\text { reg } \\
\text { Lead author [ref.] }\end{array}$} & \multicolumn{9}{|c|}{$\begin{array}{l}\text { Zandomised controlled latent tuberculosis (TB) infection treatment trials comparing efficacy of isoniazid versus other } \\
\text { egimens }\end{array}$} \\
\hline & \multirow[t]{2}{*}{ Site (year) } & \multirow[t]{2}{*}{ TST } & \multicolumn{4}{|c|}{ Cases/number treated ${ }^{\#}$} & \multicolumn{3}{|c|}{$\operatorname{RR}(95 \% \mathrm{Cl})^{\pi}$} \\
\hline & & & $\mathbf{H}$ & HR & $R Z(H)$ & $\mathbf{R}$ & HR & $\mathbf{R Z}(\mathrm{H})$ & $\mathbf{R}$ \\
\hline WHALEN [99] & Uganda (1997) & Positive & $7 / 536^{\S}$ & $9 / 556$ & $10 / 462^{f}$ & & $0.81(0.30-2.15)$ & $0.60(0.23-1.57)$ & \\
\hline MWINGA [102] & & Unknown & $9 / 122^{\# \#}$ & & $10 / 129^{\ln }$ & & & $0.95(0.40-2.26)$ & \\
\hline HALSEY [111] & Haiti (1998) & Positive & $14 / 370^{\# \#}$ & & $19 / 380^{\S \S}$ & & & $0.76(0.39-1.49)$ & \\
\hline \multirow[t]{2}{*}{ MARTINEZ [112] } & Spain (2000) & Positive & $3 / 21^{++}$ & $1 / 26$ & & & $3.71(0.42-33.15)$ & & \\
\hline & & Negative & $1 / 43^{++}$ & $1 / 43$ & & & $1.00(0.06-15.48)$ & & \\
\hline GoRDIN [113] & $\begin{array}{l}\text { International } \\
\text { (2000) }\end{array}$ & Positive & $29 / 792^{++}$ & & $28 / 791^{f f}$ & & & $1.03(0.62-1.72)$ & \\
\hline
\end{tabular}

HIV/AIDS progression stages. The optimal duration of isoniazid for the prevention of tuberculosis in HIV-seropositive individuals is also unclear. Both a 6-month regimen [99] and a 12-month regimen [98] are effective (grade A), but none of the trials directly compared isoniazid regimens of different durations. Given the uncertainty, the American Thoracic Society (ATS) discourages the use of a 6-month isoniazid regimen for patients with HIV infection [39].

From the only two available studies with long-term follow-up data $[106,107]$, the protection of isoniazid treatment in HIVinfected persons appears to be short lasting (1-2.5 yrs). As both of these studies were conducted in areas with a high incidence of tuberculosis, reinfection after completion of isoniazid preventive therapy could have been an important factor, taking into account the heightened risk of rapid progression to disease among HIV-infected subjects.

\section{ALTERNATIVE SHORT-COURSE REGIMENS}

The long duration required for the treatment of latent infection with $M$. tuberculosis triggered a series of clinical trials in search for a "short-course" regimen. Attention was naturally directed to those drugs with putative sterilising capacity against persisters $[13,14,56]$, especially rifampicin and pyrazinamide, the pivotal agents that successfully shortened the treatment duration for tuberculosis in human trials $[15,16]$.

In an animal experiment, a nonreplicating bacillary population of limited size was developed in mice vaccinated with bacille Calmette-Guérin (BCG) vaccine to mimic latent infection with M. tuberculosis [13]. After treatment with 6 months of isoniazid, 3 months of rifampicin, 2 months of rifampicin plus pyrazinamide, and 2 months of rifampicin plus pyrazinamide plus isoniazid, the proportions of mice with positive spleen cultures for M. tuberculosis were $100 \%, 20 \%, 0 \%$ and $80 \%$ respectively. The 2-month regimen of rifampicin plus pyrazinamide appeared to show the best treatment-shortening potential, and addition of isoniazid showed an antagonistic effect. These results were very encouraging, even though there could be pitfalls in extrapolating experimental observations from a murine model to man $[28,108]$.

In the 1990s, effective regimens were already fully established for the treatment of both latent infection with $M$. tuberculosis [62-74] and tuberculosis [15, 16]. In such a situation, there would be ethical and logistic difficulties in assigning a huge number of subjects to experimental preventive regimens in a manner similar to that which occurred in the 1950s [62-65]. Most of the explorative trials on alternative regimens were, therefore, carried out among groups with a very high risk for tuberculosis, such as silicosis patients [73] or HIV-infected subjects, in order to reduce the sample size and follow-up time. Only some of them contained a placebo/no treatment arm (tables 3 and 5), as it would be acceptable to compare a new regimen with the standard regimen of isoniazid for 6 or 12 months $[109,110]$. Table 6 summarises the comparison of efficacy between isoniazid and the alternative regimens, while tables 7 and 8 summarise the adverse events leading to termination of treatment in those randomised controlled trials for latent infection with $M$. tuberculosis conducted in or after the 1990s.

\section{RIFAMPICIN PLUS PYRAZINAMIDE}

In 2000, a multinational trial reported that 2 months of rifampicin and pyrazinamide was as effective as 12 months of isoniazid in reducing tuberculosis in HIV-infected individuals with latent infection with $M$. tuberculosis (table 6) [113]. Drug discontinuation was significantly higher in the rifampicin plus pyrazinamide arm 


\begin{tabular}{|c|c|c|c|c|c|c|c|c|c|c|}
\hline \multirow[t]{2}{*}{ Lead author [ref.] } & \multirow[t]{2}{*}{ Site (year) } & \multicolumn{5}{|c|}{ Cases/number treated ${ }^{\#}$} & \multicolumn{4}{|c|}{$\operatorname{RR}(95 \% \mathrm{Cl})^{\pi}$} \\
\hline & & $\mathbf{H}$ & HR & $\mathbf{R Z}(\mathrm{H})$ & $\mathbf{R}$ & Placebo & H & HR & $\mathbf{R Z}(\mathrm{H})$ & $\mathbf{R}$ \\
\hline \multicolumn{11}{|l|}{ HIV-infected } \\
\hline WHALEN [99] (anergy) & Uganda (1997) & $0 / 395^{\S}$ & & & & $0 / 323$ & $0.0(0.0-0.0)$ & & & \\
\hline GoRDIN [100] & USA (1997) & $24 / 260^{\S}$ & & & & $24 / 257$ & $0.99(0.58-1.69)$ & & & \\
\hline HAWKEN [101] & Kenya (1997) & $11 / 342^{\S}$ & & & & $5 / 342$ & $2.20(0.77-6.26)$ & & & \\
\hline MWINGA [102] & Zambia (1998) & $12 / 352^{\# \#}$ & & $14 / 351^{\operatorname{Tn}}$ & & $3 / 350$ & $3.98(1.13-13.97)$ & & $4.65(1.35-6.05)$ & \\
\hline RIVERO [104] & Spain (2003) & $6 / 83^{\S}$ & $15 / 82$ & $13 / 77^{++}$ & & $0 / 77$ & $12.07(0.69-210.76)$ & $29.13(1.77-478.67)$ & $27.00(1.63-446.3)$ & \\
\hline
\end{tabular}

RR: relative risk; $\mathrm{H}$ : isoniazid for 6-12 months; HR: isoniazid plus rifampicin daily for 3 months; $R Z(H)$ : rifampicin plus pyrazinamide or rifampicin plus pyrazinamide plus isoniazid for 2-3 months; R: rifampicin daily for 3 months. ${ }^{\#}$ : adverse events leading to termination of treatment; " : isoniazid versus regimen; ${ }^{+}$: isoniazid daily for

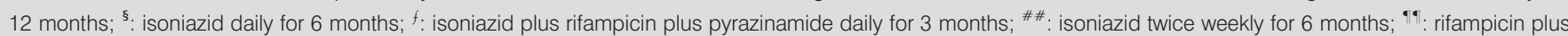
pyrazinamide twice weekly for 3 months; ${ }^{++}$: rifampicin plus pyrazinamide daily for 2 months.

TABLE 8 Comparison of serious adverse effects between isoniazid and alternative regimens in randomised trials reported after 1990

\begin{tabular}{|c|c|c|c|c|c|c|c|c|}
\hline Lead author [ref.] & Site (year) & \multicolumn{4}{|c|}{ Cases/number treated ${ }^{\#}$} & \multicolumn{3}{|c|}{$\operatorname{RR}(95 \% \mathrm{Cl})^{\pi}$} \\
\hline WHALEN [99] & Uganda (1997) & $3 / 536^{\S}$ & $13 / 556^{f}$ & $26 / 462^{\# \#}$ & & $0.24(0.07-0.84)$ & $0.10(0.03-0.33)$ & \\
\hline MWINGA [102] & Zambia (1998) & $12 / 352^{\bullet}$ & & $14 / 351^{++}$ & & & $0.85(0.40-1.82)$ & \\
\hline MARTINEZ [112] & Spain (2000) & $15 / 64^{\# \# \#}$ & $5 / 69^{f}$ & & & & $3.23(1.25-8.39)$ & \\
\hline GoRDIN [113] & International (2000) & $48 / 792^{\# \# \#}$ & & $75 / 791^{\S \S}$ & & & $0.64(0.45-0.91)$ & \\
\hline RIVERO [114] & Spain (2007) & $7 / 108^{\S}$ & $7 / 103^{f}$ & $12 / 105^{\S \S}$ & & $0.95(0.35-2.62)$ & $0.57(0.23-1.38)$ & \\
\hline \multicolumn{9}{|l|}{ Non-HIV infected } \\
\hline GIRLING [73] & Hong Kong (1992) & $13 / 173^{\S}$ & $11 / 167^{f}$ & & $7 / 172^{\bullet ⿻}$ & $1.14(0.51-2.55)$ & & $1.85(0.74-4.63)$ \\
\hline GEIJo [119] & Spain (2007) & $4 / 45^{\S}$ & $2 / 51^{f}$ & & & & & $2.27(0.42-12.38)$ \\
\hline MenzIES [120] & Canada (2004) & $8 / 58^{+1+}$ & & & $2 / 58^{f f f}$ & & & $4.00(0.85-18.64)$ \\
\hline MenZIES [121] & International (2008) & $16 / 427^{+++}$ & & & $7 / 420^{f f f}$ & & & $2.25(0.92-5.46)$ \\
\hline
\end{tabular}

RR: relative risk; $\mathrm{H}$ : isoniazid for 6-12 months; HR: isoniazid plus rifampicin daily for 3-4 months; $\mathrm{RZ}(\mathrm{H})$ : rifampicin plus pyrazinamide or rifampicin plus pyrazinamide plus isoniazid for 2-3 months; R: rifampicin daily for 3-4 months. ${ }^{*}$ : adverse events leading to termination of treatment; " : isoniazid versus regimen; ${ }^{+}$: systematic, rather

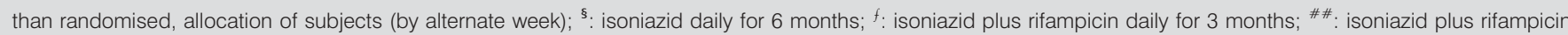
plus pyrazinamide daily for 3 months; ${ }^{\text {" }}$ : isoniazid twice weekly for 6 months; ${ }^{++}$: rifampicin plus pyrazinamide twice weekly for 3 months; ${ }^{\S}$ : rifampicin plus pyrazinamide daily for 2 months; ${ }^{f f}$ : rifampicin plus pyrazinamide twice weekly for 2 months; \#\#\#: isoniazid daily for 12 months; " ${ }^{\text {"थ }}$ : rifampicin daily for 3 months; ${ }^{+++}$: isoniazid daily for 9 months; ${ }^{\S \S}$ : isoniazid plus rifampicin daily for $3-4$ months; ${ }^{f f f}$ : rifampicin daily for 4 months. 
than the isoniazid arm (table 8). However, a lower number of patients in the rifampicin plus pyrazinamide arm had abnormal liver function test results that were grade 4 or resulted in study drug discontinuation $(11 / 791$ versus $28 / 792 ; p=0.02)$. Treatment completion was also higher for rifampicin plus pyrazinamide arm than the isoniazid arm $(80 \%$ versus $69 \%$; $<<0.001)$.

In a meta-analysis of different regimens for latent infection with M. tuberculosis among HIV-infected subjects [12], combined analysis of 428 subjects on rifampicin plus pyrazinamide for $2-3$ months and 428 subjects on placebo in two trials $[102,104]$ the combined relative risk of tuberculosis was $0.54(95 \% \mathrm{CI}$ 0.34-0.86) for rifampicin plus pyrazinamide versus placebo, even though treatment was more likely to be stopped because of adverse drug events (RR 7.84, 95\% CI 2.60-23.67). Equivalent efficacy (RR 1.03, 95\% CI 0.75-1.40) was found between isoniazid (6 or 12 months) and rifampicin plus pyrazinamide among a total of 3,409 subjects in five randomised clinical trials in the same meta-analysis (table 6) [102, 104, 111, 114]. However, the isoniazid regimen was less likely to be stopped because of adverse events (RR $0.63,95 \%$ CI $0.48-0.84$ ). Partly because of this, the proportion of patients completing treatment was higher for the shorter rifampicin plus pyrazinamide regimen in only two studies [113, 114]. Conversely, hepatotoxicity did not appear to be a prominent feature for the use of rifampicin plus pyrazinamide among HIV-infected subjects [12]. Re-analysis of the data in the trial published by GoRDIN et al. [113] in 2000 also confirmed the absence of excess hepatotoxicity risk with the combination of rifampicin plus pyrazinamide in HIV-infected individuals [122].

In another trial among HIV-infected subjects, 3 months of isoniazid plus rifampicin and pyrazinamide was equivalent to 6 months of isoniazid monotherapy and significantly reduced the risk of tuberculosis as compared to placebo [99]. However, treatment was much more likely to be stopped because of adverse events in comparison with either placebo or isoniazid (tables 7 and 8).

With the reported efficacy of a 2-month course of rifampicin and pyrazinamide in the treatment of latent infection with M. tuberculosis among the HIV-infected individuals [113], the ATS and Centers for Disease Control and Prevention (CDC) issued a joint statement in 2000 entitled "Targeted Tuberculin Testing and Treatment of Latent Tuberculosis Infection" [39]. Emphasis was put on directing tuberculin testing to populations at risk of developing tuberculosis, as well as more treatment options including short-course rifampicin-based regimens. As the drugs involved had been used extensively in the treatment of tuberculosis, there was apparently not too much concern over adverse effects. In fact, to promote better acceptance, there was call for simplified monitoring that emphasises clinical evaluation more than laboratory examination. Soon after such recommendations, reports of severe druginduced liver injury, including deaths, followed widespread use of rifampicin plus pyrazinamide [123, 124]. These reports prompted revision of the guidelines in August 2001 to reduce the dose of pyrazinamide (to $\leqslant 20 \mathrm{mg} \cdot \mathrm{kg}^{-1}$ ) and ensure closer monitoring [124]. In a national survey of 8,087 patients given rifampicin plus pyrazinamide in the USA, the frequencies of asymptomatic elevation of aspartate aminotransferase more than five times upper limit of normal and clinical hepatitis were 25.6 (95\% CI 22.3-29.3) and 18.7 (95\% CI 15.9-21.9) per 1,000 therapy initiations, respectively, with $23(2.8$ per 1,000$)$ hospitalisations and seven $(0.9$ per 1,000$)$ fatalities [125]. Increasing age, an abnormal baseline aspartate aminotransferase level (often associated with alcohol use), and unemployment within the past 24 months were found to be independent risk factors for hepatotoxicity in a cohort study on the use of 2 months of rifampicin plus pyrazinamide among jail inmates and homeless persons [126]. Such events could occur at a low pyrazinamide dose, despite biochemical monitoring, and at the end of therapy [127]. Many of these required hospitalisation and some required liver transplantation [127, 128]. Fatality was associated with higher age or use of other medications [127].

In three clinical trials involving randomised or systemic allocation of non-HIV infected subjects, $7.7 \%, 35 \%$, and $10 \%$ of those in the 2-month rifampicin plus pyrazinamide arms developed significant hepatotoxicity with aspartate or alanine aminotransferase in excess of five times the upper normal limit [115-117]. All of these proportions were significantly higher than those observed in the corresponding isoniazid arms. For unknown reasons, the frequency of hepatotoxicity in the use of rifampicin plus pyrazinamide in the treatment of latent infection with $M$. tuberculosis among non-HIV infected subjects appeared to be higher than those reported in the historical short-course trials (involving concomitant use of isoniazid, rifampicin and pyrazinamide) in the treatment of active tuberculosis $[15,16]$.

A high frequency of hepatitis of $11 \%$ to $14 \%$ was initially reported in early studies using high dosages of pyrazinamide (40-70 $\mathrm{mg} \cdot \mathrm{kg}^{-1}$ daily) in combination with isoniazid [129]. With the adoption of lower drug dosages, $2-5 \%$ of patients developed hepatitis attributable to pyrazinamide while they were put on the standard short-course regimens for treatment of tuberculosis [15, 16, 130, 131]. In the Hong Kong study [116], the reported hepatotoxicity frequency of $35 \%$ with 2 months of rifampicin plus pyrazinamide (daily dosage largely below $20 \mathrm{mg} \cdot \mathrm{kg}^{-1}$ ) was much higher than that observed among patients with silico-tuberculosis put on a 8-month regimen of streptomycin, isoniazid, rifampicin and pyrazinamide (daily dosage $30 \mathrm{mg} \cdot \mathrm{kg}^{-1}$ ) [132]. In a retrospective cohort study in the Netherlands, preventive treatment with rifampicin plus pyrazinamide caused severe hepatotoxicity more often than preventive treatment with isoniazid (OR 2.61, 95\% CI 1.265.39 ) and triple- or quadruple-drug regimens for tuberculosis (OR 2.61, 95\% CI 1.21-5.59) [133]. As the substitution of isoniazid by moxifloxcin has not been reported to increase the frequency of hepatotoxicity in a tuberculosis treatment trial [134], intrinsic differences of host status between latent infection with $M$. tuberculosis and tuberculosis might account partly for the difference in hepatotoxicity, in line with the apparent absence of excess hepatotoxicity of rifampicin plus pyrazinamide among HIV-infected subjects [12, 113]. In this regard, treatment for latent infection with $M$. tuberculosis was also terminated because of hepatotoxicity in six out of 12 consecutive African contacts of multidrug-resistant tuberculosis given pyrazinamide and ethambutol [135].

None of the randomised controlled trials among non-HIV infected are adequately powered to provide a conclusive answer on efficacy [115-117]. However, drug-induced liver 
injury is much less acceptable for preventive therapy among persons who run a $10 \%$ lifetime risk of developing tuberculosis than among persons with a potentially fatal disease if left untreated. The revised ATS/CDC recommendations now state that rifampicin plus pyrazinamide should generally not be offered to persons with latent infection with M. tuberculosis [86].

\section{RIFAMPICIN MONOTHERAPY}

Rifampicin at a dose of $10 \mathrm{mg} \cdot \mathrm{kg}^{-1}$ daily (maximum $600 \mathrm{mg}$ ) for 4 months is currently an acceptable alternative regimen for treatment of latent infection with M. tuberculosis (grade B) [39]. Only a single randomised clinical trial assessed the efficacy of rifampicin monotherapy [73]. In this study, isoniazid for 6 months, rifampicin for 3 months and isoniazid plus rifampicin for 3 months were compared against placebo. Pulmonary tuberculosis was observed in $13 \%$ of the three treatment groups combined as compared to $27 \%$ of the placebo group within 5 yrs $(\mathrm{p}<0.01)$. In the 389 patients who were followed up to $5 \mathrm{yrs}$, the 3 -month rifampicin regimen significantly reduced the risk of tuberculosis as compared to placebo (table 3). No significant difference in efficacy was observed between the isoniazid and the rifampicin arm (table 6) and acquired drug resistance did not appear to be a problem with either regimen. The rifampicin-alone therapy was very well tolerated, with serious adverse effects occurring with similar frequency as in the placebo arm (table 7). None of the 172 silicosis patients in the rifampicin arm developed hepatitis. Low frequencies of serious adverse events and high proportions of treatment completion were similarly demonstrated in later cohort studies [136-140]. In two recent randomised controlled trials among predominantly non-HIV infected individuals [120, 121], a significantly higher proportion completed treatment with 4 months of rifampicin than with 9 months of isoniazid. Adverse events leading to termination of treatment also appeared to be fewer in the rifampicin arm in both studies (table 8). In the larger study, grade 3 or 4 hepatotoxicity occurred in 16 of $422(3.8 \%)$ isoniazid recipients as compared to three of $418(0.7 \%)$ rifampicin recipients [121]. No randomised controlled trial has been published on the use of rifampicin alone in predominantly HIV-infected persons, perhaps because of concern over the possibility and consequence of acquired rifampicin resistance. In a meta-analysis involving a total of 3,586 subjects [141], noncompletion was $8.6 \%$ to $28.4 \%$ among patients who received 4 -month rifampicin therapy and $24.1 \%$ to $47.4 \%$ among patients who received 9-month isoniazid therapy (RR $0.53,95 \%$ CI 0.44-0.63). Grade 3 or 4 hepatotoxicity leading to drug discontinuation was also significantly lower ( $0 \%$ to $0.7 \%$ versus $1.4 \%$ to $5.2 \%$; RR 0.12 , $95 \%$ CI 0.05-0.30). A large scale multicentre trial is now underway to assess the effectiveness of 4-month rifampicin therapy [142]. The optimal duration of rifampicin remains uncertain. Although 3 months of rifampicin only reduced the risk of tuberculosis by $52 \%$ among silicosis patients [73], tuberculosis incidence was actually the lowest in that arm. The high residual risk could well reflect the underlying host status, rather than treatment efficacy.

\section{ISONIAZID PLUS RIFAMPICIN}

A 3-month regimen of isoniazid plus rifampicin has also been recommended as an alternative for the treatment of latent infection with $M$. tuberculosis by the British Thoracic Society (grade A) [143]. Its efficacy and adverse events leading to treatment termination were not significantly different from those of 6 months of isoniazid (tables 6 and 7). Hepatic adverse reactions (mainly elevated transaminases) also occurred at similar frequency (three cases in both arms). Additional hepatotoxicity was however shown by a meta-analysis of patients put on the combined regimen from different kinds of studies [84]. No hepatitis case was reported among 556 HIVinfected subjects in the 3-month isoniazid plus rifampicin arm in the Uganda trial [99]. In the recent Cochrane analysis among HIV-infected subjects [12], isoniazid plus rifampicin significantly reduced the risk of tuberculosis (RR 0.41, 95\% CI $0.21-$ 0.81 ) and death (RR $0.69,95 \%$ CI $0.50-0.95$ ) as compared to placebo among 1,179 subjects in two trials, but there was a higher incidence of adverse events leading to termination of treatment (RR 16.72, 95\% CI 3.29-84.89). Equivalent efficacy (RR $0.97,95 \%$ CI $0.52-1.83$ ) was observed between isoniazid (for 6 12 months) and isoniazid plus rifampicin (for 3 months) among 1,601 subjects in four trials. Adverse events leading to treatment termination were somewhat less frequent in the arm receiving isoniazid monotherapy (RR $0.79,95 \%$ CI $0.50-1.23$ ), but the difference was not statistically significant. Very similar conclusions on relative efficacy and safety of the two regimens were made in another meta-analysis of all the five trials from both HIV-infected and non-HIV infected subjects [144]. In a study among children, no clinical disease or adverse event leading to treatment termination was observed in 232 patients on 9 months of isoniazid and 238 patients on 4 months of isoniazid plus rifampicin, but patients who received isoniazid monotherapy were significantly less compliant [118]. MARTINEZ et al. [112] also reported better adherence with 3 months of isoniazid plus rifampicin as compared to 12 months of isoniazid. However, in two other studies, the proportions completing were similar between 3 months of isoniazid plus rifampicin and 6 months of isoniazid [99, 114]. An observational study among First Nations Canadians in Saskatchewan reported much higher completion ( $80 \%$ versus $19 \%$ ) for 6 months of twice weekly isoniazid plus rifampicin than for 12 months of daily, self-administered isoniazid [145]. The use of direct treatment observation in a special population could be a contributing factor.

\section{ISONIAZID PLUS RIFAPENTINE}

Rifapentine, a long-acting rifamycin, has been shown to have good activity in treatment of latent infection with $M$. tuberculosis in the mouse model, when used together with isoniazid in highly intermittent regimens [146, 147]. The combination of rifapentine $900 \mathrm{mg}$ and isoniazid $900 \mathrm{mg}$ once weekly for 12 weeks was found to be well tolerated in a recent human trial, with two out of 206 (1\%) treated contacts showing grade 3 or 4 hepatotoxicity [148]. No conclusion can be drawn on the efficacy as the comparison was made with daily rifampicin plus pyrazinamide and the number of tuberculosis cases was very low in either arm. Close to 9,000 subjects have been recruited in a large scale trial comparing 3 months of weekly isoniazid plus rifapentine with 9 months of isoniazid [149], and the results might help to establish this highly intermittent regimen for use under direct observation in the coming 2 yrs.

\section{DRUG INTERACTIONS}

Most of the clinically significant interactions involving drugs metabolised by the cytochrome P450 (CYP450) system are 
pharmacokinetic in nature [150, 151]. Rifampicin is a powerful enzyme inducer of CYP450 and may, therefore, reduce serum concentration of oral contraceptives, corticosteroids, anticoagulants, anticonvulsants, anti-infectives (including antiretrovirals), cardiovasculo-therapeutics, immunosuppressants, psychotropics, sulphonylureas, theophylline and other drugs metabolised by the same pathway [152]. As rifampicin features prominently in most of the alternative treatment options of tuberculosis preventive therapy, extra caution is called for in HIV-infected individuals [153] or among older people at higher risk of drug-drug interactions [150]. Other rifamycins, like rifapentine, might also share similar enzyme-inducing activity to varying degrees. Rifabutin, a rifamycin compound with less enzyme-inducing activity, is sometimes used in the treatment of tuberculosis in HIV-infected patients together with selected protease inhibitors or non-nucleoside reverse transcriptase inhibitors. However, dose modifications may be necessary [154].

\section{RISK OF ACQUIRING DRUG RESISTANCE}

Mutants resistant to antituberculosis drugs are known to emerge spontaneously through alterations of chromosomal genes [155]. For isoniazid, such mutants are thought to arise in one in $10^{7}$ to $10^{9}$ cell divisions, resulting in one effectively resistant $M$. tuberculosis bacillus in $10^{6}$ of the bacillary population. For rifampicin, the corresponding figures are one in $10^{10}$ cell divisions, and one in $10^{8}$ of the bacillary populations. With a bacillary load of $10^{8}$ to $10^{9}$ in a tuberculosis patient with cavitary lung lesions, combination therapy is required to prevent the selection of resistant mutants. However, while such calculations might be algebraically sound, clinical practice shows that resistance emerges against isoniazid in $0.5 \%, 2.0 \%$, and $4.0 \%$ if the companion drug is rifampicin, streptomycin or ethambutol respectively, substantially higher than those suggested by simple product rule [156].

The propensity for emergence of resistance might be less with the much lower bacillary load as is the case with latent infection with $M$. tuberculosis. In a systematic review [157] of 13 studies published since 1951, a total of 31 isoniazid-resistant isolates were obtained from the isoniazid groups and 24 from placebo/no treatment groups, giving a summary relative risk of 1.45 (95\% CI $0.85-2.47)$ in the emergence of bacillary resistance during isoniazid preventive therapy. Results were similar when studies of non-HIV infected and HIV-infected persons were considered separately. However, with the small numbers and incomplete testing of isolates, it is not possible to exclude a modest increase in risk entirely.

From a theoretical perspective, selection of rifampicin-resistant mutants may be less likely to occur than selection of isoniazidresistant mutants because of the one to three order lower spontaneous mutation rate [155]. However, rifamycin monoresistance had emerged in four of five patients with a relapse among $31 \mathrm{HIV}$-infected patients treated once weekly with isoniazid plus rifapentine in the continuation phase of treatment against tuberculosis [158]. It therefore appears that the putative low bacillary load after the end of the intensive phase of treatment is not a sufficient condition, at least not among HIV-infected patients, to prevent the emergence of resistance to a rifamycin. There is also some evidence that a higher serum level of isoniazid did appear to play a role in the prevention of rifamycin mono-resistance in the same study [159]. A number of trials have confirmed the efficacy of 3 months of isoniazid plus rifampicin (tables 3, 4 and 6), even though adding isoniazid to rifampicin is likely to increase the risk of adverse drug events, particularly drug-induced liver injury (table 8). With the concern over emergence of rifampicin resistance, there could be a case for using isoniazid plus rifampicin, especially in HIV-infected patients. However, in the only trial that directly compared 3 months of rifampicin with 3 months of isoniazid plus rifampicin [73], a smaller number of tuberculosis cases occurred in the rifampicin arm, even though the difference fell short of statistical significance. In the mouse study by LECOEUR et al. [13], isoniazid also appeared to antagonise the sterilising activity of rifampicin plus pyrazinamide. Resolution of this dilemma will have to await further studies.

\section{CONTACTS OF PATIENTS WITH DRUG-RESISTANT TUBERCULOSIS}

In an observational study among 2,795 tuberculin-positive Southeast Asian refugees prescribed isoniazid preventive therapy at the time of their resettlement in the USA [160], 19 cases of tuberculosis were detected during follow-up. 15 of them were culture positive, with eight of these isolates being isoniazid susceptible and seven isoniazid resistant. A casecontrol analysis showed that taking isoniazid for 3 months or less was associated with a six-fold increase in risk (as compared to longer treatment) for subsequent isoniazidsusceptible tuberculosis, but there was no excess risk for subsequent isoniazid-resistant disease. Conversely, taking preventive treatment (with isoniazid) as a whole has been identified as a risk factor for subsequent development of isoniazid-monoresistant tuberculosis, possibly because of prevention of disease due to isonazid-senstive strains [161]. In another observational study among 204 tuberculin skin test converters in an outbreak of isoniazid- and streptomycinresistant tuberculosis among Boston's homeless population [136], six of $71(8.6 \%)$ individuals who received no preventive chemotherapy, three of $38(7.9 \%)$ in the isoniazid group, and none of the 86 in the rifampicin or rifampicin plus isoniazid groups developed tuberculosis. These observational studies provide evidence for the obvious assumption that isoniazid monotherapy is ineffective in reducing the risk of tuberculosis due to isoniazid-resistant M. tuberculosis.

In a systematic review of treatment for latent infection with M. tuberculosis in persons at risk for multidrug-resistant tuberculosis, only two cohort studies met the inclusion criteria [162]. The earlier retrospective cohort study found isoniazid not to be effective (RR $0.46,95 \%$ CI $0.07-2.32$ ) [163], while a later prospective cohort study found individualised tailored treatment with high-dose isoniazid $\left(15-20 \mathrm{mg} \cdot \mathrm{kg}^{-1} \cdot \mathrm{day}^{-1}\right)$, pyrazinamide, ethionamide and/or ethambutol and/or ofloxacin to be effective (RR 0.20,95\% CI 0.04-0.94) [164].

In absence of sufficient data, existing recommendations are subjective and are necessarily based largely on expert opinions, rather than on clinical evidence. Rifampicin for 4 months is a rational regimen choice for the treatment of contacts infected after exposure to a source case with isoniazid-resistant tuberculosis (grade D) [39]. Opinions differ on the management of contacts of patients with multidrug-resistant tuberculosis. On 
the basis of the currently available evidence, the WHO does not recommend second-line drugs for preventive therapy among contacts putatively infected with multidrug-resistant bacilli [165]. Careful clinical follow-up for at least 2 yrs is recommended instead. If multidrug-resistant tuberculosis is diagnosed, treatment should be started promptly with an appropriate treatment regimen. In contrast to the WHO, CDC recommends 6-12 months of preventive therapy with at least two antituberculosis drugs (e.g. ethambutol and pyrazinamide or pyrazinamide and a fluoroquinolone, depending on the drug susceptibility profile of the source case's isolate) for persons likely to be infected with multidrug-resistant bacilli, especially for those thought or known to be at a high risk of progression to tuberculosis (grade D) [166]. However, high frequencies of treatment termination because of adverse events were reported for pyrazinamide-containing regimens (pyrazinamide plus ethambutol or pyrazinamide plus levofloxacin/ ofloxacin) [135, 167-169]. Hepatotoxicity was a prominent feature in some of these studies [135, 169]. Fluoroquinolones have been found to be generally well tolerated in the treatment of tuberculosis or multidrug-resistant tuberculosis [134, 170]. A question naturally arises as to the role of fluoroquinolone monotherapy in such situations. However, fluoroquinolones, in combination with second-line injectable drugs, currently play an important role in the treatment of multidrug-resistant tuberculosis [170, 171]. In a recent study, exposure to fluoroquinolones for $>10$ days, particularly $>60$ days before tuberculosis diagnosis, was associated with a high risk of fluoroquinolone-resistant tuberculosis [172]. Caution must, therefore, be exercised towards the use of fluoroquinolone monotherapy, and active surveillance remains a possible option among contacts of cases with multidrug-resistant tuberculosis, especially those at lower risk of developing clinical disease.

\section{DEVELOPMENT OF NEW DRUGS}

Clinical trials on new drugs for treatment of latent infection with $M$. tuberculosis generally lag behind those for treatment of active tuberculosis, mainly because of the logistical difficulties associated with studies in the treatment of latent infection with M. tuberculosis [173]. As mentioned in a previous section, weekly rifapentine (plus isoniazid) is being explored in the treatment of latent infection with M. tuberculosis [149] after two randomised controlled trials on the treatment of tuberculosis [174, 175].

Adenosine triphosphate (ATP) synthesis is essential in the metabolism of mycobacteria [176, 177]. TMC207 is a novel diarylquinoline with unique activity on the mycobacterial ATPsynthase [178]. In a murine model of tuberculosis, the bactericidal effect of TMC207 was modest during the first week of treatment but increased in the following 3 weeks [179]. TMC207 also showed good sterilising activity in mice. In combination with pyrazinamide, TMC207 led to bacillary sterilisation in 2 months [180]. In another mouse study on tuberculosis, TMC207 plus rifapentine plus pyrazinamide given once weekly was more active than the current standard regimen of rifampicin plus isoniazid plus pyrazinamide given five times per week [181]. In an early bactericidal activity study, significant bactericidal activity of TMC207 (400 mg) was observed from day 4 onward in a magnitude similar to that of isoniazid and rifampicin [182]. In a phase II clinical trial, the addition of TMC207 to standard therapy for multidrug-resistant tuberculosis reduced the time to culture conversion and greatly increased the proportion with culture conversion ( $48 \%$ versus $9 \%)$ at 2 months [183].

As diarylquinolines are claimed to also have bactericidal activity against nonreplicating mycobacteria [176, 177], TMC207 could be a potential candidate drug for the treatment of individuals with latent infection with $M$. tuberculosis, including contacts of patients with multidrug-resistant tuberculosis.

\section{ISSUES BEYOND EFFICACY}

As latent infection with $M$. tuberculosis is both asymptomatic and noninfectious, the primary target of intervention is to reduce the risk of progression to tuberculosis. However, on average, only a minority of latently infected individuals will develop disease in their lifetime [38-42, 47-49]. This necessarily sets a ceiling to the maximum effectiveness of treatment for latent infection with $M$. tuberculosis in terms of the number of patients to be treated to prevent an active case of tuberculosis. Figure 2 plots the number needed to treat to prevent one case of tuberculosis against the incidence of disease among the target group at different assumptions of treatment efficacies. Under all scenarios, the incidence of disease is the prime determinant of this measure of effectiveness. This would justify targeting only those at a high risk of developing tuberculosis, even at the expense of decreasing population coverage and limiting the overall impact.

Actual field practices vary widely across the world. In North America, a fairly wide range of target groups are included for screening and treatment of latent infection with $M$. tuberculosis, e.g. recent contacts, institutional clients, healthcare workers, immigrants from high incidence areas, persons with currently inactive fibrotic lesions, HIV-infected persons and subjects with other immunocompromised states, including those on immunosuppressive treatment [39, 184]. The WHO mainly focused on HIV-infected persons and young household contacts of patients with infectious pulmonary tuberculosis $[165,185]$. 9 months of isoniazid is now recommended in the USA [39] and Canada [185], while 6 months of isoniazid is still more frequently used in other parts of the world [165, 186]. Rifampicin for 4 months is an acceptable alternative regimen in the USA and Canada [39, 184], while a combination of isoniazid and rifampicin may be used more often in the UK [187]. Many factors could have entered into the strategic formulations in addition to the simple question of efficacy. With the wide variations in socioeconomic and epidemiological conditions globally, it would be necessary for each locality to set its own priority after taking into account of available scientific data and local circumstances.

\section{SAFETY AND MONITORING}

The adverse effects of current treatment regimens also constitute a major hurdle both among HIV-infected and nonHIV infected individuals (tables 7 and 8). For preventive therapy, every individual put on treatment will be subject to the potential risk of drug toxicity, but only those who would otherwise develop disease benefit from such treatment. Figure 3 shows the impact of hepatitis and disease incidence on benefit versus risk ratio in terms of number of tuberculosis 


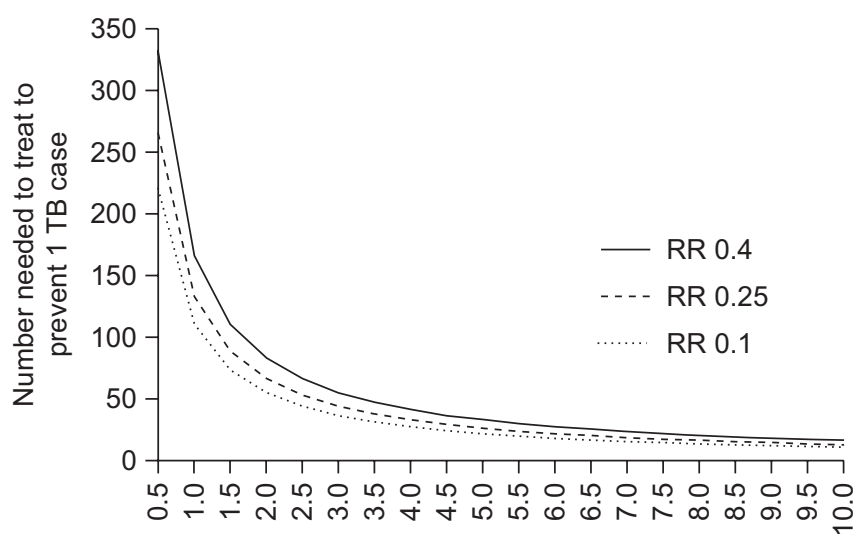

Cumulative incidence in $5 \mathrm{yrs} \%$

FIGURE 2. Impact of disease incidence on the number needed to treat to prevent one tuberculosis case within 5 yrs. RR: risk ratio of treatment versus no treatment.

cases prevented per case of hepatitis, which readily falls below one when the frequency of drug-induced liver injury is high and/or the tuberculosis incidence is low. This explains why there must generally be a much lower threshold of accepting adverse drug events during the treatment of latent infection with $M$. tuberculosis than is the case with treatment of tuberculosis.

The presence of a substantial risk in latent infection with M. tuberculosis treatment also implies a need for careful screening and close monitoring, which may add further costs and barriers of access to care. Besides patient education and clinical monitoring, baseline and monthly (or biweekly) laboratory testing of liver enzymes is recommended for chronic alcohol users, HIV-infected persons, females during pregnancy and within 3 months after delivery, and those with chronic liver disease, or taking concomitant medications that can be hepatotoxic [39, 86]. Transient transaminase elevations are common and may reflect the process of hepatic adaptation [188]. However, isoniazid and/or rifampicin should be withheld as recommended if the serum transaminase level is higher than three times the upper limit of normal in a symptomatic patient or five times the upper limit of normal in the absence of symptoms [39, 189]. With the lower degree of tolerance for risk in the treatment of latent infection with $M$. tuberculosis, reintroduction of drug is seldom attempted after significant hepatotoxicity [86].

\section{ACCEPTANCE}

Even in North America, there appears to be suboptimal acceptance of preventive therapy regimens among both clinicians and patients. Treatment of latent infection with M. tuberculosis was not recommended by the attending doctors in $20-30 \%$ of patients who appeared otherwise eligible in some studies [190, 191]. Physicians' reluctance to prescribe is especially noticeable among the older individuals, possibly related to the higher incidence of drug-induced hepatitis in the elderly [82]. Even if treatment is offered, it might be refused by considerable proportions of persons [190, 192, 193]. In a retrospective survey of public and private clinics in the USA and Canada, $123(17.1 \%)$ of 720 subjects tuberculin skin-tested

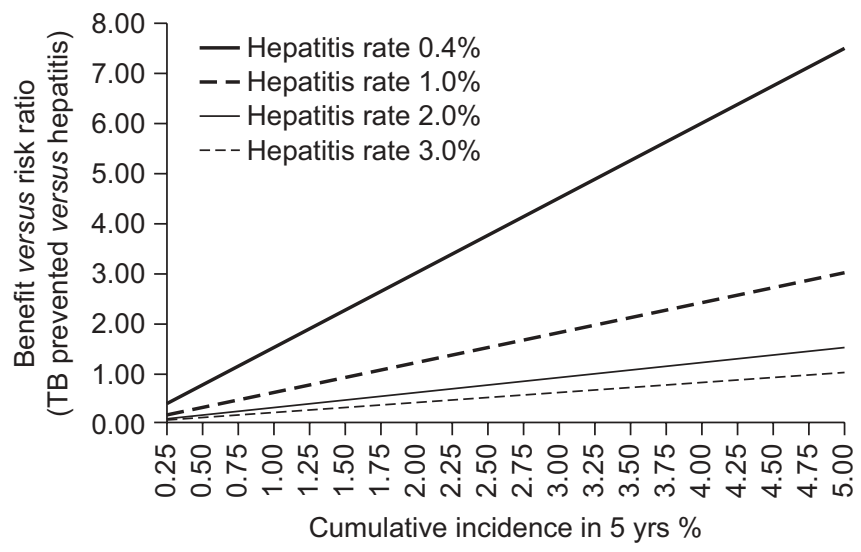

FIGURE 3. Impact of hepatitis rate and disease incidence on benefit versus risk ratios

and offered treatment in the same clinics declined treatment. Interestingly, there was a higher likelihood for healthcare workers than for other tuberculosis contacts to decline [192]. In another study among healthcare workers at an urban teaching hospital in the USA, only $69 \%$ of eligible persons accepted treatment against latent infection with M. tuberculosis [193]. These results suggested that lack of knowledge about the treatment might not be a major factor for poor acceptance.

\section{ADHERENCE}

In a systematic review of 78 studies in the USA and Canada on adherence to treatment of latent infection with $M$. tuberculosis, treatment completion varied widely (from 19\% to $96 \%$ ) but was mostly suboptimal across high-risk groups, regardless of regimen [194]. Lesser variations were observed in some of the large-scale studies in public programmes involving clients with similar characteristics. For example, $64 \%$ of treatment completion was reported in two large-scale retrospective reviews of medical records (involving 9,018 and 3,048 contacts) of individuals who were being treated with isoniazid in contact investigation programmes $[190,195]$ and in a 7-yr prospective survey of hepatotoxicity associated with isoniazid preventive therapy (involving 11,141 patients) in a public health tuberculosis clinic [85]. A similar proportion of treatment completion $(61 \%)$ was reported in a retrospective medical record review involving 19,582 treated inmates in 49 correctional facilities in the USA [196].

Similarly, treatment completion was found to be $53 \%$ in 68 public and private clinics included in a recent retrospective survey in the USA and Canada [192]. In that particular survey, a 9-month isoniazid regimen, residence in a congregate setting (nursing home, shelter or jail), injection drug use, age above 15 yrs and employment at a healthcare facility were significantly associated with failure to complete treatment. However, associations between adherence and patient factors, clinic facilities or treatment characteristics were inconsistent across other studies [194]. Adherence is a composite behavioural endpoint. Heterogeneity in social context, provider arrangement and client profile could well have accounted for these variations. While there are suggestions that shorter durations of treatment may improve treatment completion, the higher frequency of adverse events leading to treatment termination 
for some of the short-course regimens might nullify such effects, especially for rifampicin plus pyrazinamide, and possibly isoniazid plus rifampicin [12].

\section{COST-EFFECTIVENESS}

A number of economic analyses have been conducted on the effectiveness of the treatment of latent infection with M. tuberculosis [197-206]. Most of them were performed under a number of epidemiological, healthcare utilisation and costing assumptions and might not be applicable outside the specific economic realities of industrialised countries for which they were modelled. Under such assumptions, the use of isoniazid in the treatment of latent infection with $M$. tuberculosis has been found consistently to be cost-effective and often cost-saving in populations that are younger, and/or at greater risk to progress from disease. However, not all of them have taken a full account of the direct or indirect screening costs [197, 198]. Most of them based the analysis on highly defined target groups, especially recent tuberculin skin test converters [197, 199] or tuberculin skin test-positive close contacts in low tuberculosis incidence settings [197, 198]. While these defined target groups might be more easily accessible and have a higher screening yield, high disease incidence, fewer adverse effects and lower monitoring cost, they might account only for a relatively small proportion of all the tuberculosis cases within a community. Among older tuberculin skin test reactors, the conclusions were either small positive health effects at a cost considered acceptable in developed economies [197], or in an opposite direction [200]. As it is not always easy to delineate science clearly from assumptions or value judgements in some of these modelling exercises [207], the findings might have to be taken with a grain of salt.

In a more recent cost-benefit analysis that included both screening and treatment for latent infection with $M$. tuberculosis in Germany [201], cost of screening and treatment based on a positive result in a QuantiFERON ${ }_{\circledast}$ TB Gold In-Tube (QFT) test alone amounted to 215.79 euro per close contact, less than that of dual step-testing (227.89 euro) or using the tuberculin skin test alone (232.58 euro). The cost-effectiveness of QFT-based procedures were sensitive to low treatment completion or increasing price, but the relationship between the strategies remained robust when the disease-predicting power of QFT was lowered to that for the tuberculin skin test in a sensitivity analysis. It therefore appears that the potentially higher specificity of QFT may help to improve cost-effectiveness of targeted screening of latent infection with M. tuberculosis in a low-incidence setting.

In a cost-effective analysis [202] comparing 6 months and 12 months of isoniazid in the treatment of patients with fibrotic lung lesions in the IUAT trial [72], the cost per case prevented was US\$7,112 for the 6-month regimen, compared with US $\$ 16,024$ for the 12-month regimen, and each additional case prevented by the 12-month regimen would cost US\$80,807. Therefore, the 6-month regimen appeared to be more costeffective, at least under the level of treatment completion and effectiveness as observed in that trial and the costs then prevailing in the USA. The lack of difference between the 6month and the 12-month arm was based on all patients, and not on patients actually taking the drugs as prescribed. It might be argued that a cost-effectiveness study of a treatment regimen should be based on efficacy under optimised situations, rather than effectiveness before it is being well accepted [76, 208]. However, in situations where acceptance and adherence to such preventive treatment are likely to remain suboptimal in absence of major breakthroughs in the current diagnostic and treatment tools, there could be an equally valid challenge to this counter-argument from a pragmatic perspective. Like efficacy, no study has compared the cost-effectiveness of 6 months and 9 months of isoniazid.

Alternative regimens were assessed in other cost-effectiveness analyses. JASMER et al. [203] used a Markov model to conduct a cost-effectiveness analysis based on frequency of adverse events and completion of the two treatment regimens in a recent clinical trial. Although 2 months of rifampicin plus pyrazinamide and 9 months of isoniazid both increased life expectancy by 1.2 yrs as compared to no treatment, the shortcourse regimen cost US $\$ 273$ more per patient over a range of completion frequencies. In another modelling study focusing on tuberculin skin test converters after recent exposure to an infectious index case, 4 months of rifampicin was cost-saving compared with 9-month therapy of self-administered isoniazid, and directly observed isoniazid plus rifapentine once weekly for 3 months is cost-saving for extremely high-risk patients and cost-effective for lower-risk patients [199].

In a decision and cost-effectiveness analysis on hypothetical HIV-infected patients with CD4 counts of 200 cells $\cdot \mathrm{mm}^{-3}$ or less and positive results on tuberculin skin tests [206], isoniazid for 6 months or 12 months, isoniazid and rifampicin for 3 months, and rifampicin and pyrazinamide for 2 months were all cost-saving, but a 3-month regimen of isoniazid, rifampicin and pyrazinamide was not. Short-course preventive therapy appears to be a reasonable alternative to the 12-month isoniazid regimen.

\section{CLINICAL PERSPECTIVES}

The purpose of this section is to summarise the clinically relevant aspects of what is known on the subject, so as to facilitate clinical decision by the practising physicians.

\section{How is latent infection with M. tuberculosis defined?}

Latency, as assayed by the tuberculin skin test and IGRA, is a state of persistent mycobacteria-specific T-cell responses in the absence of clinical evidence for tuberculosis disease. Such an operational definition is necessitated by the immunodiagnostic nature of the currently available tools. Whether persisting mycobacteria-specific T-cell responses depend on the presence of living mycobacteria is not entirely clear.

\section{What is the risk for the development of tuberculosis in an individual with latent infection with $\mathrm{M}$. tuberculosis?}

Among individuals with positive tuberculin skin test results identified during tuberculosis contact tracing who did not receive preventive chemotherapy, approximately $2-5 \%$ will develop active disease in the first 2 yrs (grade B). The risk of tuberculosis may be substantially higher in individuals identified by a positive IGRA tests result, but conclusive data are still missing (grade D). The disease risk among test-positive persons is likely to be much lower in absence of recent contact exposure (grade C). It is also heavily influenced by age and other host factors (grade C). 
Why should we treat latent infection with M. tuberculosis?

Treatment of latent infection by $M$. tuberculosis offers personal protection for individuals at risk of developing tuberculosis (grade A). Its contribution towards epidemiological impact, however, varies with the local epidemiological situation, and depends very much on the success of containing ongoing transmission through the effective diagnosis and treatment of infectious tuberculosis sources (grade D).

\section{Is treatment against latent infection with $\mathrm{M}$. tuberculosis cost-effective?}

A targeted approach is necessary in order to maximise the costeffectiveness in the screening and treatment of latent infection with M. tuberculosis. The treatment of latent infection with M. tuberculosis has been found consistently to be cost-effective among target groups with high risk of tuberculosis in industrialised countries (grade B).

\section{Who should be evaluated for the presence of latent infection with $\mathrm{M}$. tuberculosis?}

Widely accepted target groups for screening include children and young adults who have recently been in close contact with a case of infectious tuberculosis (grade A), HIV-infected subjects (grade A) and candidates for tumour necrosis factor antagonist therapies (grade A). Controversies exist for other less clearly defined risk groups under different social and epidemiological settings, e.g. immigrants, healthcare workers and patients with chronic renal failure. A consensus development process through open consultation by a local authoritative body may provide valuable guidance to the individual clinician (grade D). Sufficient information over benefits and risks should be provided to the targeted subjects to allow an informed choice. In general, screening is indicated only for individuals willing to receive treatment on basis of the screening result.

\section{Do the tuberculin skin test and IGRAs differ in the ability to diagnose latent infection with $\mathrm{M}$. tuberculosis?}

As the IGRAs are not affected by BCG vaccination (grade B), they may offer an advantage over tuberculin skin test among
BCG-vaccinated individuals (grade C). However, neither test is able to distinguish between recent and remote infection, or reliably predict the subsequent development of tuberculosis. Before a tuberculin skin test or IGRA is administered, the clinician should have a clear idea of what target condition (infection or disease) to screen for and the pre-test odds of that condition in the target group being screened. Application of the likelihood ratios will allow the estimation of the post-test odds (pre-test odds multiplied by the likelihood ratio) across different clinical and epidemiological settings [209, 210].

\section{Which regimen should be used for the treatment of latent infection with $\mathrm{M}$. tuberculosis?}

From currently available data, the recommended regimen for treatment of latent infection with $M$. tuberculosis remains isoniazid for 6, preferably 12 and, perhaps optimally, 9 months among both HIV-infected and non-HIV-infected persons (grade A). 4 months of rifampicin (grade B) and 3 months of isoniazid plus rifampicin (grade A) are acceptable alternatives. Rifampicin alone should be considered if isoniazid is contraindicated or where drug tolerance is a major concern, while isoniazid plus rifampicin may be preferred among HIVinfected individuals (grade D).

\section{How efficacious is treatment against latent infection with M. tuberculosis?}

The protective efficacy of 12 months of isoniazid may exceed $90 \%$ (grade B), even though field effectiveness may be substantially lower as a result of nonadherence (grade A). From limited long-term data on 6 months of isoniazid and other alternative regimens, the protection appears to be shortlasting among HIV-infected persons in areas with high incidence of tuberculosis (grade B).

\section{What is the optimal treatment duration for isoniazid preventive therapy?}

Currently, there is no consensus over the optimal treatment duration for isoniazid preventive therapy. Patient acceptance, drug adherence, adverse effects and cost-effectiveness are some of the relevant factors for consideration in formulating

TABLE 9 Grading of evidences for recommendations (Scottish Intercollegiate Guidelines Network)

\begin{tabular}{|c|c|c|c|c|}
\hline $\begin{array}{l}\text { Study } \\
\text { rating }\end{array}$ & Study design & Number of studies & Target population & $\begin{array}{l}\text { Grades of } \\
\text { recommendation }\end{array}$ \\
\hline $1++$ & $\begin{array}{l}\text { High quality meta-analyses, systematic reviews of RCTs, or RCTs with } \\
\text { a very low risk of bias }\end{array}$ & At least one study & Directly applicable & A \\
\hline $1+$ & $\begin{array}{l}\text { Well-conducted meta-analyses, systematic reviews, or RCTs with a low } \\
\text { risk of bias }\end{array}$ & Studies with overall consistency & Directly applicable & A \\
\hline $1++/ 1+$ & As above & Studies with overall consistency & Extrapolated & B \\
\hline \multirow[t]{2}{*}{$2++$} & High-quality case-control/cohort studies or their systemic reviews, with very & Studies with overall consistency & Directly applicable & B \\
\hline & low risk of confounding/bias and high probability of causal relationship & Studies with overall consistency & Extrapolated & C \\
\hline \multirow[t]{2}{*}{$2+$} & Well-conducted case-control/cohort studies with low risk of confounding/bias & Studies with overall consistency & Directly applicable & C \\
\hline & and moderate probability of causal relationship & Studies with overall consistency & Extrapolated & D \\
\hline 3 & Nonanalytic studies, e.g. case reports and case series & & & D \\
\hline 4 & Expert opinion & & & D \\
\hline
\end{tabular}

$\mathrm{RCT}$ : randomised controlled trial 
local recommendations. If these issues are not of concern, there may be a valid case for using a longer duration of 9-12 months, especially among HIV-infected persons (grade D).

\section{What is the optimal therapy to prevent tuberculosis in contacts of patients with multidrug-resistant and extensively drug-resistant tuberculosis with a positive tuberculin skin test or IGRA result?}

The optimal therapy for treatment of latent infection with a presumably multidrug-resistant $M$. tuberculosis strain is currently not known. Active surveillance of contacts of multidrugresistant tuberculosis remains a possible option, especially for those at lower risk of developing clinical disease (grade D).

\section{APPENDIX}

The grading of evidence for recommendations, according to the Scottish Intercollegiate Guidelines Network, can be found in table 9 .

\section{STATEMENT OF INTEREST}

None declared.

\section{REFERENCES}

1 Gutierrez MC, Brisse S, Brosch R, et al. Ancient origin and gene mosaicism of the progenitor of Mycobacterium tuberculosis. PLoS Pathog 2005; 1: e5.

2 Grigg ER. The arcana of tuberculosis. Am Rev Tuberc Pulmon Dis 1958; 78: 151-172.

3 Lange C, Mori T. Advances in the diagnosis of tuberculosis. Respirology 2010; 15: 220-240.

4 Yew WW, Lange C, Leung CC. Treatment of tuberculosis: 2010 update. Eur Respir J 2011; 37: 441-462.

5 World Health Organization. Global tuberculosis control: a short update to the 2009 report. WHO/HTM/TB/2009.426. Geneva, World Health Organization, 2009.

6 Dye C, Scheele S, Dolin P, et al. Consensus statement. Global burden of tuberculosis: estimated incidence, prevalence, and mortality by country. WHO Global Surveillance and Monitoring Project. JAMA 1999; 282: 677-686.

7 Mack U, Migliori GB, Sester M, et al. LTBI: latent tuberculosis infection or lasting immune responses to M. tuberculosis? A TBNET consensus statement. Eur Respir J 2009; 33: 956-973.

8 Canetti G. Les réinfections tuberculeuses latentes du poumon. Etude anatomo-pathologique, bactériologique et pathogénique des lésions tuberculeuses abortives autres que de primoinfection. [Anatomical-pathological, bacteriological, and pathogenetic study of abortive, non-primary tuberculosis lesions.] Paris, Vigot Frères, 1939.

9 Chan-Yeung M, Tam CM, Wong $\mathrm{H}$, et al. Molecular and conventional epidemiology of tuberculosis in Hong Kong: a population-based prospective study. J Clin Microbiol 2003; 41: 2706-2708.

10 Ferebee SH, Mount FW, Palmer CE. Tuberculosis prophylaxis trials in review. Public Health Rep 1957; 72: 703-704.

11 Smieja M, Marchetti C, Cook D, et al. Isoniazid for preventing tuberculosis in non-HIV infected persons. Cochrane Database Syst Rev 1999; 1: CD001363.

12 Akolo C, Adetifa I, Shepperd S, et al. Treatment of latent tuberculosis infection in HIV infected persons. Cochrane Database Syst Rev 2010; 1: CD000171.

13 Lecoeur HF, Truffot-Pernot C, Grosset JH. Experimental shortcourse preventive therapy of tuberculosis with rifampin and pyrazinamide. Am Rev Respir Dis 1989; 140: 1189-1193.
14 Dhillon J, Dickinson JM, Sole K, et al. Preventive chemotherapy of tuberculosis in Cornell model mice with combinations of rifampin, isoniazid, and pyrazinamide. Antimicrob Agents Chemother 1996; 40: 552-555.

15 British Thoracic and Tuberculosis Association. Short-course chemotherapy in pulmonary tuberculosis: a controlled trial by the British Thoracic and Tuberculosis Association. Lancet 1976; 2: 1102-1104.

16 Hong Kong/British Medical Research Council. Controlled trial of four thrice-weekly regimens and a daily regimen all given for 6 months for pulmonary tuberculosis. Lancet 1981; 1: 171-174.

17 Chapuis L, Ji B, Truffot-Pernot C, et al. Preventive therapy of tuberculosis with rifapentine in immunocompetent and nude mice. Am J Respir Crit Care Med 1994; 150: 1355-1362.

18 Rosenthal IM, Zhang M, Williams KN, et al. Daily dosing of rifapentine cures tuberculosis in three months or less in the murine model. PLoS Med 2007; 4: e344.

19 Zhang T, Zhang M, Rosenthal IM, et al. Short-course therapy with daily rifapentine in a murine model of latent tuberculosis infection. Am J Respir Crit Care Med 2009; 180: 1151-1157.

20 Nuermberger EL, Yoshimatsu T, Tyagi S, et al. Moxifloxacincontaining regimens of reduced duration produce a stable cure in murine tuberculosis. Am J Respir Crit Care Med 2004; 170: 1131-1134.

21 Rosenthal IM, Zhang M, Almeida D, et al. Isoniazid or moxifloxacin in rifapentine-based regimens for experimental tuberculosis? Am J Respir Crit Care Med 2008; 178: 989-993.

22 Veziris N, Ibrahim M, Lounis N, et al. A once-weekly R207910containing regimen exceeds activity of the standard daily regimen in murine tuberculosis. Am J Respir Crit Care Med 2009; 179: 75-79.

23 Scottish Intercollegiate Guidelines Network. SIGN 50: A guideline developer's handbook, Annex B. www.sign.ac.uk/ guidelines/fulltext/50/annexb.html Date last accessed: February 2, 2010.

24 Parrish NM, Dick JD, Bishai WR. Mechanisms of latency in Mycobacterium tuberculosis. Trends Microbiol 1998; 6: 107-112.

25 Tufariello JM, Chan J, Flynn JL. Latent tuberculosis: mechanisms of host and bacillus that contribute to persistent infection. Lancet Infect Dis 2003; 3: 578-590.

26 Ehlers S. Lazy, dynamic or minimally recrudescent? On the elusive nature and location of the mycobacterium responsible for latent tuberculosis. Infection 2009; 37: 87-95.

27 Cardona PJ. A dynamic reinfection hypothesis of latent infection with M. tuberculosis. Infection 2009; 37: 80-86.

28 Rustad TR, Sherrid AM, Minch KJ, et al. Hypoxia: a window into Mycobacterium tuberculosis latency. Cell Microbiol 2009; 11 1151-1159.

29 Wayne LG, Lin KY. Glyoxylate metabolism and adaptation of Mycobacterium tuberculosis to survival under anaerobic conditions. Infect Immun 1982; 37: 1042-1049.

30 Paramasivan CN, Sulochana S, Kubendiran G, et al. Bactericidal action of gatifloxacin, rifampin, and isoniazid on logarithmicand stationary-phase cultures of Mycobacterium tuberculosis. Antimicrob Agents Chemother 2005; 49: 627-631.

$31 \mathrm{Hu}$ Y, Coates AR, Mitchison DA. Sterilising action of pyrazinamide in models of dormant and rifampicin-tolerant Mycobacterium tuberculosis. Int J Tuberc Lung Dis 2006; 10: 317-322.

32 Leistikow RL, Morton RA, Bartek IL, et al. The Mycobacterium tuberculosis DosR regulon assists in metabolic homeostasis and enables rapid recovery from non-respiring dormancy. J Bacteriol 2009; 192: 1662-1670.

33 Kana BD, Gordhan BG, Downing KJ, et al. The resuscitationpromoting factors of Mycobacterium tuberculosis are required for virulence and resuscitation from dormancy but are collectively dispensable for growth in vitro. Mol Microbiol 2008; 67: 672-684. 
34 Hu Y, Mangan JA, Dhillon J, et al. Detection of mRNA transcripts and active transcription in persistent Mycobacterium tuberculosis induced by exposure to rifampin or pyrazinamide. J Bacteriol 2000; 182: 6358-6365.

35 Mccune RM Jr, Mcdermott W, Tompsett R. The fate of Mycobacterium tuberculosis in mouse tissues as determined by the microbial enumeration technique. II. The conversion of tuberculous infection to the latent state by the administration of pyrazinamide and a companion drug. J Exp Med 1956; 104: 763-802.

36 American Thoracic Society. Diagnostic standards and classification of tuberculosis in adults and children. Am J Respir Crit Care Med 2000; 161: 1376-1395.

37 Thompson BC. Survival rates in pulmonary tuberculosis. BMJ 1943; 2: 721.

38 Styblo K. Epidemiology of tuberculosis. Royal Netherlands Tuberculosis Association Selected Papers. The Hague, Royal Netherlands Tuberculosis Association, 1991.

39 American Thoracic Society, Centers for Disease Control and Prevention and Infectious Diseases Society of America. Targeted tuberculin testing and treatment of latent tuberculosis infection. Am J Respir Crit Care Med 2000; 161: S221-S247.

40 Comstock GW, Livesay VT, Woolpert SF. The prognosis of a positive tuberculin reaction in childhood and adolescence. Am J Epidemiol 1974; 99: 131-138.

41 Vynnycky E, Fine PEM. Life time risks, incubation period, and serial interval of tuberculosis. Am J Epidemiol 2000; 152: 247-263.

42 Marais BJ, Gie RP, Schaaf HS, et al. The natural history of childhood intra-thoracic tuberculosis: a critical review of literature from the pre-chemotherapy era. Int J Tuberc Lung Dis 2004; 8: 392-402.

43 Leung CC, Li T, Lam TH, et al. Smoking and tuberculosis among the elderly in Hong Kong. Am J Respir Crit Care Med 2004; 170: 1027-1033.

44 Leung CC, Lam TH, Chan WM, et al. Lower risk of tuberculosis in obesity. Arch Intern Med 2007; 167: 1297-1304.

45 Leung CC, Lam TH, Chan WM, et al. Diabetic control and risk of tuberculosis: a cohort study. Am J Epidemiol 2008; 167: 1486-1494.

46 Leung CC, Lam TH, Ho KS, et al. Passive smoking and tuberculosis. Arch Intern Med 2010; 170: 287-292.

47 Diel R, Loddenkemper R, Meywald-Walter K, et al. Predictive value of a whole blood IFN- $\gamma$ assay for the development of active tuberculosis disease after recent infection with Mycobacterium tuberculosis. Am J Respir Crit Care Med 2008; 177: 1164-1170.

48 Bakir M, Millington K, Soysal A, et al. Prognostic value of a T-cell-based, interferon- $\gamma$ biomarker in children with tuberculosis contact. Ann Intern Med 2008; 149: 777-787.

49 Hill PC, Jackson-Sillah DJ, Fox A, et al. Incidence of tuberculosis and the predictive value of ELISPOT and Mantoux tests in Gambian case contacts. PLoS One 2008; 3: e1379.

50 Leung CC, Chang KC. Role of interferon gamma release assays in tuberculosis. Respirology 2009; 14: 156-158.

51 Pai M, Zwerling A, Menzies D. Systematic review: T-cell-based assays for the diagnosis of latent tuberculosis infection: an update. Ann Intern Med 2008; 149: 177-184.

52 Karam F, Mbow F, Fletcher $\mathrm{H}$, et al. Sensitivity of IFN- $\gamma$ release assay to detect latent tuberculosis infection is retained in HIV infected patients but dependent on HIV / AIDS progression. PLoS One 2008; 3: e1441.

53 Leidl L, Mayanja-Kizza H, Sotgiu G, et al. Relationship of immunodiagnostic assays for tuberculosis and numbers of circulating CD4+ T-cells in HIV infection. Eur Respir J 2010; 35 619-626.

54 Goletti D, Butera O, Vanini V, et al. Response to Rv2628 latency antigen associates with cured tuberculosis and remote infection. Eur Respir J 2010; 36: 135-142.
55 Krummel B, Strassburg A, Ernst M, et al. Low frequency of Mycobacterium tuberculosis transmission among close contacts of a highly symptomatic index case. PLoS One 2010; 5: e11670.

56 Mitchison D. Basic mechanisms of chemotherapy. Chest 1979; 76: Suppl., 771-781.

57 Jindani A, Doré CJ, Mitchison DA. Bactericidal and sterilizing activities of antituberculosis drugs during the first 14 days. Am J Respir Crit Care Med 2003; 167: 1348-1354.

58 Mitchison DA. Assessment of new sterilizing drugs for treating pulmonary tuberculosis by culture at 2 months. Am Rev Respir Dis 1993; 147: 1062-1063.

59 Medical Research Council. Various combinations of isoniazid with streptomycin or with PAS in the treatment of pulmonary tuberculosis: Seventh report to the Medical Research Council by their Tuberculosis Chemotherapy Trials Committee. BMJ 1955; 1 : 434-445.

60 Ferebee SH, Hopwood L, Palmer CE. Studies on prevention of experimental tuberculosis with isoniazid. II. Effects of different dosage regimens. Am Rev Tuberc 1956; 74: 917-939.

61 Ferebee S, Mount FW, Nastasiades A. Prophylactic effects of isoniazid on primary tuberculosis in children; a preliminary report. Am Rev Tuberc 1957; 76: 942-963.

62 Comstock GW. Isoniazid prophylaxis in an undeveloped area Am Rev Respir Dis 1962; 86: 810-822.

63 Ferebee SH, Mount FW. Tuberculosis morbidity in a controlled trial of the prophylactic use of isoniazid among household contacts. Am Rev Respir Dis 1962; 85: 490-510.

64 Mount FW, Ferebee SH. The effect of isoniazid prophylaxis on tuberculosis morbidity among household contacts of previously known cases of tuberculosis. Am Rev Respir Dis 1962; 85: 821-827.

65 Ferebee SH, Mount FW, Murray FJ, et al. A controlled trial of isoniazid prophylaxis in mental institutions. Am Rev Respir Dis 1963; 88: 161-175.

66 Ferebee SH. Controlled chemoprophylaxis trials in tuberculosis A general review. Adv Tuberc Res 1970; 17: 28-106.

67 Hsu KHK. Thirty years after isoniazid. Its impact on tuberculosis in children and adolescents. JAMA 1984; 251: 1283-1285.

68 Egsmose T, Ang'awa JOW, Poti SJ. The use of isoniazid among household contacts of open cases of pulmonary tuberculosis. Bull World Health Organ 1965; 33: 419-433.

69 Del Castillo H, Bautista LD, Jacinto CP, et al. Chemoprophylaxis in the Philippines. A controlled pilot study among household contacts of tuberculosis cases. Bull Quezon Institute 1965; 7 277-290.

70 Veening GJJ. Long term isoniazid prophylaxis. Controlled trial on INH prophylaxis after recent tuberculin conversion in young adults. Bull Int Un Against Tuber 1968; 41: 169-171.

71 Falk A, Fuchs GF. Prophylaxis with isoniazid in inactive tuberculosis. A Veterans Administration cooperative study XII Chest 1978; 73: 44-48.

72 International Union Against Tuberculosis, Committee on Prophylaxis. Efficacy of various durations of isoniazid preventive therapy for tuberculosis. Bull World Health Organ 1982; 60: $555-564$

73 Hong Kong Chest Service/Tuberculosis Research Centre, Madras/British Medical Research Council. A double-blind placebo-controlled clinical trial of three antituberculosis chemoprophylaxis regimens in patients with silicosis in Hong Kong. Am Rev Respir Dis 1992; 145: 36-41.

74 John GT, Thomas PP, Thomas M, et al. A double-blind randomized controlled trial of primary isoniazid prophylaxis in dialysis and transplant patients. Transplantation 1994; 57 1683-1684.

75 Comstock GW, Baum C, Snider DE Jr. Isoniazid prophylaxis among Alaskan Eskimos: a final report of the Bethel Isoniazid Studies. Am Rev Respir Dis 1979; 119: 827-830. 
76 Comstock GW. How much isoniazid is needed for prevention of tuberculosis among immunocompetent adults? Int J Tuberc Lung Dis 1999; 3: 847-850.

77 Taylor Z, Nolan CM, Blumberg HM, et al. Controlling tuberculosis in the United States: recommendations from the American Thoracic Society, CDC, and the Infectious Diseases Society of America. MMWR Recomm Rep 2005; 54: 1-81.

78 Cohn DL, Catlin BJ, Peterson KL, et al. A 62-dose, 6-month therapy for pulmonary and extrapulmonary tuberculosis. A twice-weekly, directly observed, and cost-effective regimen. Ann Intern Med 1990; 112: 407-415.

79 McIlleron $\mathrm{H}$, Willemse M, Werely CJ, et al. Isoniazid plasma concentrations in a cohort of South African children with tuberculosis: implications for international pediatric dosing guidelines. Clin Infect Dis 2009; 48: 1547-1553.

80 Scharer L, Smith JP. Serum transaminase elevations and other hepatic abnormalities in patients receiving isoniazid. Ann Intern Med 1969; 71: 1113-1120.

81 Garibaldi RA, Drusin RE, Ferebee SH, et al. Isoniazid-associated hepatitis. Report of an outbreak. Am Rev Respir Dis 1972; 106: 357-365.

82 Kopanoff DE, Snider DE, Caras GJ. Isoniazid-related hepatitis: A US Public Health Service cooperative surveillance study. Am Rev Respir Dis 1978; 117: 991-1001.

83 Comstock GW. Prevention of tuberculosis among tuberculin reactors: maximizing benefits, minimizing risks. JAMA 1986; 256: 2729-2730.

84 Steele MA, Burk RF, DesPrez RM. Toxic hepatitis with isoniazid and rifampin. A meta-analysis. Chest 1991; 99: 465-471.

85 Nolan CM, Goldberg SV, Buskin SE. Hepatotoxicity associated with isoniazid preventive therapy: a 7-year survey from a public health tuberculosis clinic. JAMA 1999; 281: 1014-1018.

86 Centers for Disease Control and Prevention/American Thoracic Society. Update: Adverse event data and revised American Thoracic Society/CDC recommendations against the use of rifampin and pyrazinamide for treatment of latent tuberculosis infection - United States, 2003. MMWR 2003; 52: 735-739.

87 Goldman AL, Braman SS. Isoniazid: a review with emphasis on adverse effects. Chest 1972; 62: 71-77.

88 Girling DJ. Adverse effects of antituberculosis drugs. Drugs 1982; 23: 56-74.

89 Blumberg HM, Burman WJ, Chaisson RE, et al. American Thoracic Society/Centers for Disease Control and Prevention/ Infectious Diseases Society of America: treatment of tuberculosis. Am J Respir Crit Care Med 2003; 167: 603-662.

90 World Health Organization. Treatment of Tuberculosis. Guidelines for National Programmes: 4th Edn. WHO/HTM/TB/2009.420. Geneva, World Health Organization, 2010.

91 Yew WW. Chemotherapy including drug-resistant therapy and future developments. In: Davies PDO, Barnes PF, Gordon SB, eds. Clinical Tuberculosis. 4th Edn. Oxford, Hodder Arnold, 2008; pp. 225-242.

92 Snider DE Jr. Pyridoxine supplementation during isoniazid therapy. Tubercle 1980; 61: 191-196.

93 Selwyn PA, Hartel D, Lewis VA, et al. A prospective study of the risk of tuberculosis among intravenous drug users with human immunodeficiency virus infection. N Engl J Med 1989; 320: $545-550$.

94 Williams BG, Dye C. Antiretroviral drugs for tuberculosis control in the era of HIV/AIDS. Science 2003; 301: 1535-1537.

95 Girardi E, Sabin CA, d'Arminio Monforte A, et al. Incidence of tuberculosis among HIV-infected patients receiving highly active antiretroviral therapy in Europe and North America. Clin Infect Dis 2005; 41: 1772-1782.

96 Watkins RE, Brennan R, Plant AJ. Tuberculin reactivity and the risk of tuberculosis: a review. Int J Tubercle Lung Dis 2000; 4: 895-903.
97 Aichelburg MC, Rieger A, Breitenecker F, et al. Detection and prediction of active tuberculosis disease by a whole-blood interferon- $\gamma$ release assay in HIV-1-infected individuals. Clin Infect Dis 2009; 48: 954-962.

98 Pape JW, Jean SS, Ho JL, et al. Effect of isoniazid prophylaxis on incidence of active tuberculosis and progression of HIV infection. Lancet 1993; 342: 268-272.

99 Whalen CC, Johnson JL, Okwera A, et al. A trial of three regimens to prevent tuberculosis in Ugandan adults infected with the human immunodeficiency virus. Uganda-Case Western Reserve University Research Collaboration. N Engl J Med 1997; 337: 801-808.

100 Gordin FM, Matts JP, Miller C, et al. A controlled trial of isoniazid in persons with anergy and human immunodeficiency virus infection who are at high risk for tuberculosis. Terry Beirn Community Programs for Clinical Research on AIDS. N Engl J Med 1997; 337: 315-320.

101 Hawken MP, Meme HK, Elliott LC, et al. Isoniazid preventive therapy for tuberculosis in HIV-1-infected adults: results of a randomized controlled trial. AIDS 1997; 11: 875-882.

102 Mwinga A, Hosp M, Godfrey-Faussett P, et al. Twice weekly tuberculosis preventive therapy in HIV infection in Zambia AIDS 1998; 12: 2447-2457.

103 Fitzgerald DW, Severe P, Joseph P, et al. No effect of isoniazid prophylaxis for purified protein derivative-negative HIV infected adults living in a country endemic tuberculosis: results of a randomized trial. J Acquir Immune Defic Syndr 2001; 28: 305-307.

104 Rivero A, Lopez-Cortes L, Castillo R, et al. A randomized trial of three regimens to prevent tuberculosis in HIV-infected patients with anergy. Enferm Infecc Microbiol Clin 2003; 21: 287-292.

105 Mohammed A, Myer L, Ehrlich R, et al. Randomised controlled trial of isoniazid preventive therapy in South African adults with advanced HIV disease. Int J Tuberc Lung Dis 2007; 11: 1114-1120.

106 Johnson JL, Okwera A, Hom DL, et al. Duration of efficacy of treatment of latent tuberculosis infection in HIV-infected adults. AIDS 2001; 15: 2137-2147.

107 Quigley MA, Mwinga A, Hosp M, et al. Long-term effect of preventive therapy for tuberculosis in a cohort of HIV-infected Zambian adults. AIDS 2001; 15: 215-222.

108 Mitchison DA, Chang KC. Experimental tuberculosis of tuberculosis: can we trust the mouse? Am J Respir Crit Care Med 2009; 180: 201-202.

109 World Medical Association. The Declaration of Helsinki: Ethical Principles for Medical Research Involving Human Subjects. www.wma.net/e/ethicsunit/helsinki.htm Last updated: 2002. Date last accessed: February 10, 2010.

110 International Conference on Harmonisation of Technical Requirements for Registration of Pharmaceuticals for Human Use. E6: Good Clinical Practice: Consolidated Guideline. Published in the Federal Register, May 9, 1997; 62: 25691-25709..

111 Halsey NE, Coberly JS, Desormeaux J, et al. Randomized trial of isoniazid versus rifampicine and pyrazinamide for prevention of tuberculosis in HIV-1 infection. Lancet 1998; 351: 786-792.

112 Martinez AEM, Cuadra F, Solera J, et al. Evaluation of 2 tuberculosis chemoprohylaxis regimens in patients infected with human immunodeficiency virus. The Gecmei Group. Medicina Clinica (Barcelona) 2000; 115: 161-165.

113 Gordin F, Chaisson RE, Matts JP, et al. Rifampin and pyrazinamide $v s$ isoniazid for prevention of tuberculosis in HIV-Infected persons. An international randomized trial. JAMA 2000; 283: $1445-1450$.

114 Rivero A, López-Cortés L, Castillo R, et al. A randomized clinical trial investigating three chemoprophylaxis regimens for latent tuberculosis infection in HIV-infected patients. Enferm Infecc Microbiol Clin 2007; 25: 305-310. 
115 Jasmer RM, Saukkonen JJ, Blumberg HM, et al. Short-course rifampin and pyrazinamide compared with isoniazid for latent tuberculosis infection: a multicenter clinical trial. Ann Intern Med 2002; 137: 640-647.

116 Leung CC, Law WS, Chang KC, et al. Initial experience on rifampin and pyrazinamide $v s$ isoniazid in the treatment of latent tuberculosis infection among patients with silicosis in Hong Kong. Chest 2003; 124: 2112-2118.

117 Tortajada C, Martinez-Lacasa J, Sanchez F, et al. Tuberculosis Prevention Working Group. Is the combination of pyrazinamide plus rifampicin safe for treating latent tuberculosis infection in persons not infected by the human immunodeficiency virus? Int J Tuberc Lung Dis 2005; 9: 276-281.

118 Spyridis NP, Spyridis PG, Gelesme A, et al. The effectiveness of a 9-month regimen of isoniazid alone versus 3- and 4-month regimens of isoniazid plus rifampin for treatment of latent tuberculosis infection in children: results of an 11-year randomized study. Clin Infect Dis 2007; 45: 715-722.

119 Geijo MP, Herranz CR, Vaño D, et al. Short-course isoniazid and rifampin compared with isoniazid for latent tuberculosis infection: a randomized clinical trial. Enferm Infecc Microbiol Clin 2007; 25: 300-304.

120 Menzies D, Dion MJ, Rabinovitch B, et al. Treatment completion and costs of a randomized trial of rifampin for 4 months versus isoniazid for 9 months. Am J Respir Crit Care Med 2004; 170: 445-449.

121 Menzies D, Long R, Trajman A, et al. Adverse events with 4 months of rifampin therapy or 9 months of isoniazid therapy for latent tuberculosis infection: a randomized trial. Ann Intern Med 2008; 149: 689-697.

122 Gordin FM, Cohn DL, Matts JP, et al. Hepatotoxicity of rifampin and pyrazinamide in the treatment of latent tuberculosis infection in HIV-infected persons: is it different than in HIVuninfected persons? Clin Infect Dis 2004; 39: 561-565.

123 Fatal and severe hepatitis associated with rifampin and pyrazinamide for the treatment of latent tuberculosis infection New York and Georgia, 2000. MMWR Morb Mortal Wkly Rep 2001; 50: 289-291.

124 Centers for Disease Control and Prevention/American Thoracic Society: Update: fatal and severe liver injuries associated with rifampin and pyrazinamide for latent tuberculosis infection, and revisions in American Thoracic Society/ CDC recommendations - United States, 2001. MMWR Morb Mortal Wkly Rep 2001; 50: 733-735.

125 McElroy PD, Ijaz K, Lambert LA, et al. National survey to measure rates of liver injury, hospitalization, and death associated with rifampin and pyrazinamide for latent tuberculosis infection. Clin Infect Dis 2005; 41: 1125-1133.

126 Lobato MN, Reves RR, Jasmer RM, et al. Adverse events and treatment completion for latent tuberculosis in jail inmates and homeless persons. Chest 2005; 127: 1296-1303.

127 Ijaz K, Jereb JA, Lambert LA, et al. Severe or fatal liver injury in 50 patients in the United States taking rifampin and pyrazinamide for latent tuberculosis infection. Clin Infect Dis 2006; 42: 346-355.

128 Kunimoto D, Warman A, Beckon A, et al. Severe hepatotoxicity associated with rifampin-pyrazinamide preventative therapy requiring transplantation in an individual at low risk for hepatotoxicity. Clin Infect Dis 2003; 36: e158-e161.

129 Campagna M, Calix A, Hauser G. Observations on the combined use of pyrazinamide (Aldinamide) and isoniazid in the treatment of pulmonary tuberculosis; a clinical study. Am Rev Tuberc 1954; 69: 334-350.

130 Yee D, Valiquette C, Pelletier M, et al. Incidence of serious side effects from first-line antituberculosis drugs among patients treated for active tuberculosis. Am J Respir Crit Care Med 2003; 167: 1472-1477.
131 Chang KC, Leung CC, Yew WW, et al. Hepatotoxicity of pyrazinamide: cohort and case-control analyses. Am J Respir Crit Care Med 2008; 177: 1391-1396.

132 Hong Kong Chest Service/Tuberculosis Research Centre, Madras/British Medical Research Council. A controlled clinical comparison of 6 and 8 months of antituberculosis chemotherapy in the treatment of patients with silicotuberculosis in Hong Kong. Am Rev Respir Dis 1991; 143: 262-267.

133 van Hest R, Baars H, Kik S, et al. Hepatotoxicity of rifampinpyrazinamide and isoniazid preventive therapy and tuberculosis treatment. Clin Infect Dis 2004; 39: 488-496.

134 Dorman SE, Johnson JL, Goldberg S, et al. Substitution of moxifloxacin for isoniazid during intensive phase treatment of pulmonary tuberculosis. Am J Respir Crit Care Med 2009; 180: 273-280.

135 Younossian AB, Rochat $\mathrm{T}$, Ketterer JP, et al. High hepatotoxicity of pyrazinamide and ethambutol for treatment of latent tuberculosis. Eur Respir J 2005; 26: 462-464.

136 Polesky A, Farber HW, Gottlieb DJ, et al. Rifampin preventive therapy for tuberculosis in Boston's homeless. Am J Respir Crit Care Med 1996; 154: 1473-1477.

137 Villarino ME, Ridzon R, Weismuller PC, et al. Rifampin preventive therapy for tuberculosis infection: experience with 157 adolescents. Am J Respir Crit Care Med 1997; 155: 1735-1738.

138 Page KR, Sifakis F, Montes de Oca R, et al. Improved adherence and less toxicity with rifampin $v s$ isoniazid for treatment of latent tuberculosis: a retrospective study. Arch Intern Med 2006; 166: $1863-1870$

139 Lardizabal A, Passannante M, Kojakali F, et al. Enhancement of treatment completion for latent tuberculosis infection with 4 months of rifampin. Chest 2006; 130: 1712-1717.

140 Haley CA, Stephan S, Vossel LF, et al. Successful use of rifampicin for Hispanic foreign-born patients with latent tuberculosis infection. Int J Tuberc Lung Dis 2008; 12: 160-167.

141 Ziakas PD, Mylonakis E. 4 months of rifampin compared with 9 months of isoniazid for the management of latent tuberculosis infection: a meta-analysis and cost-effectiveness study that focuses on compliance and liver toxicity. Clin Infect Dis 2009; 49: 1883-1889.

142 A Randomized Clinical Trial Comparing 4RIF vs. 9INH for Treatment of Latent Tuberculosis Infection (LTBI) - Effectiveness. http://clinicaltrials.gov/ct2/show/NCT00931736 Date last updated: August 10, 2010. Date last accessed: March 31, 2010.

143 Joint Tuberculosis Committee of the British Thoracic Society Control and prevention of tuberculosis in the United Kingdom: code of practice 2000. Thorax 2000; 55: 887-901.

144 Ena J, Valls V. Short-course therapy with rifampin plus isoniazid, compared with standard therapy with isoniazid, for latent tuberculosis infection: a meta-analysis. Clin Infect Dis 2005; 40: 670-676.

$145 \mathrm{McNab}$ BD, Marciniuk DD, Alvi RA, et al. Twice weekly isoniazid and rifampin treatment of latent tuberculosis infection in Canadian plains Aborigines. Am J Respir Crit Care Med 2000; 162: 989-993.

146 Chapuis L, Ji B, Truffot-Pernot C, et al. Preventive therapy of tuberculosis with rifapentine in immunocompetent and nude mice. Am J Respir Crit Care Med 1994; 150: 1355-1362.

147 Miyazaki E, Chaisson RE, Bishai WR. Analysis of rifapentine for preventive therapy in the Cornell mouse model of latent tuberculosis. Antimicrob Agents Chemother 1999; 43: 2126-2130.

148 Schechter M, Zajdenverg R, Falco G, et al. Weekly rifapentine/ isoniazid or daily rifampin/pyrazinamide for latent tuberculosis in household contacts. Am J Respir Crit Care Med 2006; 173: 922-926.

149 TBTC Study 26: Weekly RFP/INH for 3 mo. vs. Daily INH for 9 mo. for the Treatment of LTBI. http://clinicaltrials.gov/ct2/ 
show/NCT00023452 Date last updated: July 26, 2010. Date last accessed: March 31, 2010.

150 Yew WW. Clinically significant interactions with drugs used in the treatment of tuberculosis. Drug Saf 2002; 25: 111-133.

151 Niemi M, Backman JT, Fromm MF, et al. Pharmacokinetic interactions with rifampicin. Clin Pharmacokinet 2003; 42: 819-850.

152 Baciewicz AM, Chrisman CR, Finch CK, et al. Update on rifampin and rifabutin drug interactions. Am J Med Sci 2008; 335: 126-136.

153 Burman WJ, Gallicano K, Peloquin C. Therapeutic implications of drug interactions in the treatment of human immunodeficiency virus-related tuberculosis. Clin Infect Dis 1999; 28: 419-430.

154 Cohen K, Meintjes G. Management of individuals requiring antiretroviral therapy and TB treatment. Curr Opin HIV AIDS 2010; 5: 61-69.

155 World Health Organization. Anti-tuberculosis Drug Resistance in the World. WHO/TB/97.229. Geneva, World Health Organization, 1997.

156 Mitchison DA. Treatment of tuberculosis. The Mitchell Lecture 1979. J Roy Coll Phys London 1980; 14: 91-99.

157 Balcells ME, Thomas SL, Godfrey-Faussett P, et al. Isoniazid preventive therapy and risk for resistant tuberculosis. Emerg Infect Dis 2006; 12: 744-751.

158 Vernon A, Burman W, Benator D, et al. Acquired rifamycin monoresistance in patients with HIV-related tuberculosis treated with once-weekly rifapentine and isoniazid. Tuberculosis Trials Consortium. Lancet 1999; 353: 1843-1847.

159 Weiner M, Burman W, Vernon A, et al. Low isoniazid concentrations and outcome of tuberculosis treatment with onceweekly isoniazid and rifapentine. Am J Respir Crit Care Med 2003; 167: 1341-1347.

160 Nolan CM, Aitken ML, Elarth AM, et al. Active tuberculosis after isoniazid chemoprophylaxis of Southeast Asian refugees. Am Rev Respir Dis 1986; 133: 431-436.

161 Cattamanchi A, Dantes RB, Metcalfe JZ, et al. Clinical characteristics and treatment outcomes of patients with isoniazidmonoresistant tuberculosis. Clin Infect Dis 2009; 48: 179-185.

162 Fraser A, Paul M, Attamna A, et al. Treatment of latent tuberculosis in persons at risk for multidrug-resistant tuberculosis: systematic review. Int J Tuberc Lung Dis 2006; 10: 19-23.

163 Schaaf HS, Gie RP, Kennedy M, et al. Evaluation of young children in contact with adult multidrug-resistant pulmonary tuberculosis: a 30-month follow-up. Pediatrics 2002; 109: 765-771.

164 Schaaf H S, Vermeulen H A, Gie R P, et al. Evaluation of young children in household contact with adult multidrugresistant pulmonary tuberculosis cases. Pediatr Infect Dis J 1999; 8: 494-500.

165 World Health Organization Stop TB Partnership Childhood TB Subgroup. Chapter 4: childhood contact screening and management. [Official Statement. Guidance for National Tuberculosis Programmes on the management of tuberculosis in children. Chapter 4 in the series.] Int J Tuberc Lung Dis 2007; 11: 12-15.

166 Centers for Disease Control and Prevention. Management of persons exposed to multidrugresistant tuberculosis. MMWR Recomm Rep 1992; 41: 59-71.

167 Lou HX, Shullo MA, McKaveney TP. Limited tolerability of levofloxacin and pyrazinamide for multidrug-resistant tuberculosis prophylaxis in a solid organ transplant population. Pharmacotherapy 2002; 22: 701-704.

168 Papastavros T, Dolovich LR, Holbrook A, et al. Adverse events associated with pyrazinamide and levofloxacin in the treatment of latent multidrug-resistant tuberculosis. CMAJ 2002; 167: 131-136.
169 Ridzon R, Meador J, Maxwell R, et al. Asymptomatic hepatitis in persons who received alternative preventive therapy with pyrazinamide and ofloxacin. Clin Infect Dis 1997; 24: 1264-1265.

170 Yew WW, Chan CK, Leung CC, et al. Comparative roles of levofloxacin and ofloxacin in the treatment of multidrugresistant tuberculosis: preliminary results of a retrospective study from Hong Kong. Chest 2003; 124: 1476-1481.

171 World Health Organization. Guidelines for the Programmatic Management of Drug-Resistant Tuberculosis - Emergency Update 2008. WHO/HTM/TB/2008.402. Geneva, World Health Organization, 2008. WHO/HTM/TB/2008.402.

172 Devasia RA, Blackman A, Gebretsadik T, et al. Fluoroquinolone resistance in Mycobacterium tuberculosis: the effect of duration and timing of fluoroquinolone exposure. Am J Respir Crit Care Med 2009; 180: 365-370.

173 Global Alliance for TB Drug Development. Scientific blueprint for tuberculosis drug development. Tuberculosis 2001; 81: Suppl. $1,1-52$.

174 Tam CM, Chan SL, Lam CW, et al. Rifapentine and isoniazid in the continuation phase of treating pulmonary tuberculosis: initial report. Am J Respir Crit Care Med 1998; 157: 1726-1733.

175 Benator D, Bhattacharya M, Bozeman L, et al. Rifapentine and isoniazid once a week versus rifampicin and isoniazid twice a week for treatment of drug-susceptible pulmonary tuberculosis in HIV-negative patients: a randomised clinical trial. Lancet 2002; 360: 528-534.

176 Rao S, Alonso S, Rand L, et al. The protonmotive force is required for maintaining ATP homeostasis and viability of hypoxic, nonreplicating Mycobacterium tuberculosis. Proc Natl Acad Sci USA 2008; 105: 11945-11950.

177 Koul A, Vranckx L, Dendouga N, et al. Diarylquinolines are bactericidal for dormant mycobacteria as a result of disturbed ATP homeostasis. J Biol Chem 2008; 283: 25273-25280.

178 Andries K, Verhasselt P, Guillemont J, et al. A diarylquinoline drug active on the ATP synthase of Mycobacterium tuberculosis. Science 2005; 307: 223-227.

179 Lounis N, Gevers T, Van Den Berg J, et al. Impact of the interaction of R207910 with rifampin on the treatment of tuberculosis studied in the mouse model. Antimicrob Agents Chemother 2008; 52: 3568-3572.

180 Ibrahim M, Andries K, Lounis N, et al. Synergistic activity of R207910 combined with pyrazinamide against murine tuberculosis. Antimicrob Agents Chemother 2007; 51: 1011-1015.

181 Veziris N, Ibrahim M, Lounis N, et al. A once-weekly R207910containing regimen exceeds activity of the standard daily regimen in murine tuberculosis. Am J Respir Crit Care Med 2009; 179: 75-79.

182 Rustomjee R, Diacon AH, Allen J, et al. Early bactericidal activity and pharmacokinetics of the diarylquinoline TMC207 in treatment of pulmonary tuberculosis. Antimicrob Agents Chemother 2008; 52: 2831-2835.

183 Diacon AH, Pym A, Grobusch $\mathrm{M}$, et al. The diarylquinoline TMC207 for multidrug-resistant tuberculosis. N Engl J Med 2009; 360: 2397-2405.

184 Public Health Agency of Canada and Canadian Lung Association. Canadian Tuberculosis Standards. Ottawa, Public Health Agency of Canada and Canadian Lung Association, 2007.

185 World Health Organization. TB/HIV Clinical Manual. Geneva, World Health Organization, 2008.

186 National Institute for Health and Clinical Excellence. Clinical Diagnosis and Management of Tuberculosis, and Measures for its Prevention and Control. London, National Institute for Health and Clinical Excellence, 2006.

187 Ormerod LP. Rifampicin and isoniazid prophylactic chemotherapy for tuberculosis. Arch Dis Child 1998; 78: 169-171.

188 Saukkonen JJ, Cohn DL, Jasmer RM, et al. Hepatotoxicity of Antituberculosis Therapy Subcommittee. An official ATS 
statement: hepatotoxicity of antituberculosis therapy. Am J Respir Crit Care Med 2006; 174: 935-952.

189 Blumberg HM, Leonard MK Jr, Jasmer RM. Update on the treatment of tuberculosis and latent tuberculosis infection. JAMA 2005; 293: 2776-2784.

190 Jereb J, Etkind SC, Joglar OT, et al. Tuberculosis contact investigations: outcomes in selected areas of the United States, 1999. Int J Tuberc Lung Dis 2003; 7: S384-S390.

191 Yuan L, Richardson E, Kendall PR. Evaluation of a tuberculosis screening program for high-risk students in Toronto schools CMAJ 1995; 153: 925-932.

192 Horsburgh CR Jr, Goldberg S, Bethel J, et al. Latent tuberculosis infection treatment acceptance and completion in the United States and Canada. Chest 2010; 137: 401-409.

193 LoBue PA, Catanzaro A. Effectiveness of a nosocomial tuberculosis control program at an urban teaching hospital. Chest 1998; 113: 1184-1189.

194 Hirsch-Moverman Y, Daftary A, Franks J, et al. Adherence to treatment for latent tuberculosis infection: systematic review of studies in the US and Canada. Int J Tuberc Lung Dis 2008; 12: 1235-1254.

195 Sprinson JE, Flood J, Fan CS, et al. Evaluation of tuberculosis contact investigations in California. Int J Tuberc Lung Dis 2003; 7: Suppl. 3, S363-S368.

196 Lobato MN, Leary LS, Simone PM. Treatment for latent TB in correctional facilities: a challenge for TB elimination. Am J Prev Med 2003; 24: 249-253.

197 Rose DN, Schechter CB, Fahs MC, et al. Tuberculosis prevention: cost-effectiveness analysis of isoniazid chemoprophylaxis. Am J Prev Med 1988; 4: 102-109.

198 Diel R, Nienhaus A, Schaberg T. Cost-effectiveness of isoniazid chemoprevention in close contacts. Eur Respir J 2005; 26: 465-473.

199 Holland DP, Sanders GD, Hamilton CD, et al. Costs and cost-effectiveness of four treatment regimens for latent tuberculosis infection. Am J Respir Crit Care Med 2009; 179 1055-1060.

200 Tsevat J, Taylor W C, Wong J B, et al. Isoniazid for the tuberculin reactor: take it or leave it. Am Rev Respir Dis 1988; 137: 215-220.

201 Diel R, Schaberg T, Loddenkemper R, et al. Enhanced costbenefit analysis of strategies for LTBI screening and INH chemoprevention in Germany. Respir Med 2009; 103: 1838-1853.

202 Snider DE Jr, Caras GJ, Koplan JP. Preventive therapy with isoniazid. Cost-effectiveness of different durations of therapy. JAMA 1986; 255: 1579-1583.

203 Jasmer RM, Snyder DC, Saukkonen JJ, et al. Short-course rifampin and pyrazinamide compared with isoniazid for latent tuberculosis infection: a cost-effectiveness analysis based on a multicenter clinical trial. Clin Infect Dis 2004; 38: 363-369.

204 Nolan CM, Roll L, Goldberg SV, et al. Directly observed isoniazid preventive therapy for released jail inmates. Am J Respir Crit Care Med 1997; 155: 583-586.

205 Bandyopadhyay T, Murray H, Metersky ML. Cost-effectiveness of tuberculosis prophylaxis after release from short-term correctional facilities. Chest 2002; 121: 1771-1775.

206 Rose DN. Short-course prophylaxis against tuberculosis in HIVinfected persons. A decision and cost-effectiveness analysis. Ann Intern Med 1998; 129: 779-786.

207 Snider DE Jr. Decision analysis for isoniazid preventive therapy: take it or leave it? Am Rev Respir Dis 1988; 137: 2-4.

208 Ait-Khaled N, Alarcon E, Bissell K, et al. Isoniazid preventive therapy for people living with HIV: public health challenges and implementation issues. Int J Tuberc Lung Dis 2009; 13: 927-935.

209 Grimes DA, Schulz KF. Refining clinical diagnosis with likelihood ratios. Lancet 2005; 365: 1500-1505.

210 Chang KC, Leung CC. Systematic review of interferon- $\gamma$ release assays in tuberculosis: focus on likelihood ratios. Thorax 2010; 65: 271-276. 